\title{
The Associated Regulatory Mechanisms of Zinc Lactate in Redox Balance and Mitochondrial Function of Intestinal Porcine Epithelial Cells
}

\author{
Wenjie Tang, ${ }^{1,2,3}$ Jing Long, ${ }^{1}$ Tiejun $\mathrm{Li}^{4}{ }^{4}$ Lingyuan Yang, ${ }^{3}$ Jianzhong $\mathrm{Li} \mathbb{\mathbb { D }},{ }^{1}$ Liuqin $\mathrm{He} \mathbb{D}^{1,}, 4$ \\ Shuwei Li, ${ }^{2}$ Shengyao Kuang $@{ }^{2}$ Yanzhong Feng, ${ }^{5}$ Heshu Chen, ${ }^{5}$ Fenglan Li, ${ }^{6}$ Zhiliang Du, \\ and Yulong Yin $\mathbb{1 D}^{3,4}$ \\ ${ }^{1}$ Hunan Provincial Key Laboratory of Animal Intestinal Function and Regulation, College of Life Sciences, Hunan Normal University, \\ Changsha 410081, China \\ ${ }^{2}$ Sichuan Academy of Animal Sciences, Animal Breeding and Genetics key Laboratory of Sichuan Province, Chengdu 610066, China \\ ${ }^{3}$ College of Animal Science and Technology, Hunan Agricultural University, Changsha, Hunan 410128, China \\ ${ }^{4}$ CAS Key Laboratory of Agro-ecological Processes in Subtropical Region, Institute of Subtropical Agriculture, Hunan Provincial Key \\ Laboratory of Animal Nutritional Physiology and Metabolic Process, National Engineering Laboratory for Pollution Control and \\ Waste Utilization in Livestock and Poultry Production, Changsha 410125, China \\ ${ }^{5}$ Heilongjiang Academy of Academy of Agricultural Sciences, Harbin 150086, China \\ ${ }^{6}$ College of Life Sciences, Northeast Agricultural University, Harbin 150030, China \\ ${ }^{7}$ Cloud Computing Center, Chinese Academy of Sciences, Dongguan 523808, China
}

Correspondence should be addressed to Jianzhong Li; ljzhong@hunnu.edu.cn, Liuqin He; 285687180@qq.com, Shengyao Kuang; ksy_cd@163.com, and Yulong Yin; yinyulong@isa.ac.cn

Received 16 August 2020; Revised 18 September 2020; Accepted 30 November 2020; Published 18 December 2020

Academic Editor: Ana Cipak Gasparovic

Copyright (C) 2020 Wenjie Tang et al. This is an open access article distributed under the Creative Commons Attribution License, which permits unrestricted use, distribution, and reproduction in any medium, provided the original work is properly cited.

Zinc lactate (ZnLA) is a new organic zinc salt which has antioxidant properties in mammals and can improve intestinal function. This study explored the effects of $\mathrm{ZnLA}$ and $\mathrm{ZnSO}_{4}$ on cell proliferation, $\mathrm{Zn}$ transport, antioxidant capacity, mitochondrial function, and their underlying molecular mechanisms in intestinal porcine epithelial cells (IPEC-J2). The results showed that addition of ZnLA promoted cell proliferation, inhibited cell apoptosis and IL-6 secretion, and upregulated the mRNA expression and concentration of MT-2B, ZNT-1, and CRIP, as well as affected the gene expression and activity of oxidation or antioxidant enzymes (e.g., CuZnSOD, CAT, and Gpx1, GSH-PX, LDH, and MDA), compared to $\mathrm{ZnSO}_{4}$ or control. Compared with the control, ZnLA treatment had no significant effect on mitochondrial membrane potential, whereas it markedly increased the mitochondrial basal OCR, nonmitochondrial respiratory capacity, and mitochondrial proton leakage and reduced spare respiratory capacity and mitochondrial reactive oxygen (ROS) production in IPEC-J2 cells. Furthermore, ZnLA treatment increased the protein expression of Nrf2 and phosphorylated AMPK, but reduced Keap1 and p62 protein expression and autophagy-related genes LC3B-1 and Beclin mRNA abundance. Under $\mathrm{H}_{2} \mathrm{O}_{2}$-induced oxidative stress conditions, ZnLA supplementation markedly reduced cell apoptosis and mitochondrial ROS levels in IPEC-J2 cells. Moreover, ZnLA administration increased the protein expression of $\mathrm{Nrf2}$ and decreased the protein expression of caspase-3, Keap1, and p62 in $\mathrm{H}_{2} \mathrm{O}_{2}$-induced IPEC-J2 cells. In addition, when the activity of AMPK was inhibited by Compound C, ZnLA supplementation did not increase the protein expression of nuclear Nrf2, but when Compound C was removed, the activities of AMPK and Nfr2 were both increased by ZnLA treatment. Our results indicated that ZnLA could improve the antioxidant capacity and mitochondrial function in IPEC-J2 cells by activating the AMPK-Nrf2-p62 pathway under normal or oxidative stress conditions. Our novel finding also suggested that $\mathrm{ZnLA}$, as a new feed additive for piglets, has the potential to be an alternative for $\mathrm{ZnSO}_{4}$. 


\section{Introduction}

Zinc $(\mathrm{Zn})$, one of the most important trace elements in mammals, has been reported to reduce the incidence of diarrhea and improve the structure and function of the intestinal barrier in postweaning piglets [1-4]. Extracellular and intracellular $\mathrm{Zn}^{2+}$ in mammalian cells play a key role in physiological or pathological processes, including growth, immunity, and nutrient metabolism [5]. Previous reports have confirmed that $\mathrm{Zn}$ deficiency in animals led to a decrease in the number of $\mathrm{T}$ cells [6], oxidative stress, intestinal dysfunction, and inflammatory cell infiltration $[4,7,8]$. Traditionally, inorganic $\mathrm{Zn}$ (oxides and sulfates) has served as a feed additive to promote growth performance in livestock. To date, $\mathrm{Zn}$ additives in the market are in various types, such as zinc oxide, zinc sulfate, and nanozinc, all of which have a benefit in $\mathrm{Zn}$ absorption and combating diarrhea [9-13]. However, the excessive use and low absorption efficiency of inorganic $\mathrm{Zn}$ in livestock and poultry breeding resulted in the deposition of heavy metals in animal products and the high production of excrement, which inevitably caused concerns in meat safety and environmental pollution $[14,15]$.

Zinc lactate (ZnLA) is chemically synthesized from feedgrade zinc oxide and $D L$-lactic acid and can easily bind with ligands or metal carriers in enterocytes, which plays a key role in antioxidant function and immune response in animals. Previous studies have reported that the relative bioavailability of ZnLA in animal production is higher than that of inorganic $\mathrm{Zn}$ and can improve the growth performance of animals [16]. For example, the addition of ZnLA to animal feed improved the utilization of serum free amino acids and meat quality (e.g., average shell strength and shell thickness) and reduced the shell-breaking rate in chickens $[17,18]$. Dietary ZnLA supplementation could also increase the birth weight and weaning survival rate in rabbits, as well as enhance fur elasticity and brightness [19]. Recent reports have indicated that organic $\mathrm{Zn}$ in pigs is more helpful in adjusting the adaptive response to piglets' oxidative stress compared with inorganic $\mathrm{Zn}$ [20]. However, the effect mechanisms of ZnLA on the antioxidant and anti-inflammatory ability in pigs have not been well-studied.

It is known that nuclear factor erythroid 2-related factor 2 (Nrf2), a principal key transcription factor, has been considered as the main stress regulator that activates the antioxidant system. Upon exposure to various stressors, the release of Nrf2 from Kelch-like ECH-associated protein 1 (Keap1) translocates into the nucleus, resulting in the expression of various cytoprotective genes [21]. Recent studies have reported that Nrf2 could be activated by AMP-activated protein kinase $(\mathrm{AMPK})$ and modulate autophagy-related genes (e.g., p62, Beclin, and LC3B-1/2) to participate in the alleviation of oxidative stress in mammalian cells [22]. Autophagyrelated protein p62 can inhibit Nrf2 degradation and promote Nrf2 stability and nuclear translocation by interfering with Keap1-Nrf2 interaction to participate in the cellular antioxidative stress response [23]. However, whether ZnLA could protect against oxidative stress by modulating AMPK-Nrf2 activation and autophagy signals is still poorly understood. Moreover, mitochondria are the main energy source of cells, where they play an important role in cell pro- cesses such as apoptosis, reactive oxygen species (ROS) generation, cell cycle, and thermogenesis. Oxidative damage leads to ROS production and mitochondrial dysfunction [24]. A previous study showed that the combination of $\mathrm{Zn}$ and selenium improved mitochondrial function and alleviated oxidative stress caused by Alzheimer's disease [24]. Therefore, the purpose of this study was to compare the effects of $\mathrm{ZnLA}$ and $\mathrm{ZnSO}_{4}$ on cell proliferation and autophagy, Zn transport, antioxidant capacity, and mitochondrial function in intestinal porcine epithelial cells (IPEC-J2) and to reveal the associated regulatory mechanism of ZnLA in $\mathrm{H}_{2} \mathrm{O}_{2}$-induced oxidative stress in IPEC-J2 cells.

\section{Materials and Methods}

2.1. Cell Culture. The IPEC-J2 cells derived from the jejunal epithelia of the neonatal piglets were used in all studies to assess the related mechanisms in vitro. IPEC-J2 cells were grown in uncoated plastic culture flasks in Dulbecco's Modified Eagle Medium (DMEM), 10\% fetal calf serum (FBS; Hyclone, UT, USA), $5 \mathrm{mM}$ L-glutamine, and $1 \%$ antibiotics (100 U/mL penicillin and $100 \mathrm{U} / \mathrm{mL}$ streptomycin) and cultured at $37^{\circ} \mathrm{C}$ with $5 \% \mathrm{CO}_{2}$. The media was changed every two days, and the $\mathrm{pH}$ of all cell culture media was maintained at 7.4. The cells covered the bottom of the culture bottle and were trypsinized into a six-well plate and cultured at $37^{\circ} \mathrm{C}$ with $5 \% \mathrm{CO}_{2}$. When cells were grown to $70-80 \%$ confluence, the cells were cultured in treatment mediums. The cells were then collected to determine the relevant indicators.

2.2. Cell Viability Assays. IPEC-J2 cells were seeded in a 96well plate at a density of $8 \times 10^{3}$ cells/well and grown to $80 \%$ confluence. Cells were treated with DMEM containing ZnLA (99\%; Sichuan Zoology Feed Co. Ltd.) and $\mathrm{ZnSO}_{4}$ with final $\mathrm{Zn}$ concentrations of $0,0.1,0.5,1,2.5,5,7.5,10,15$, and $20 \mathrm{mg} / \mathrm{L}$. After incubation for $6,12,24,36,48$, and $60 \mathrm{~h}$, cell viability was evaluated by cell counting kits (CKK-8) (Dojindo, Kumamoto, Japan) using a microplate reader at $450 \mathrm{~nm}$ according to the manufacturer's instructions.

2.3. Cell Treatment. At $\sim 70-80 \%$ confluence, $\mathrm{ZnLA}_{\text {or }} \mathrm{ZnSO}_{4}$ was added to fresh medium without FBS, which contained the same amount of $\mathrm{Zn}(7.5 \mathrm{mg} / \mathrm{L})$. In order to eliminate the interference of lactic acid, equal amounts of lactic acid and $\mathrm{Zn}$ compared with the $\mathrm{ZnLA}$ group were used. To induce oxidative stress, $200 \mu \mathrm{M} \mathrm{H}_{2} \mathrm{O}_{2}$ (Sigma-Aldrich, MO, USA) was used as previously reported [25]. Compound $\mathrm{C}(5 \mu \mathrm{M})$ (Selleck, Shanghai, China), an AMPK inhibitor, was added to the medium to inhibit AMPK activity.

2.4. Intracellular Enzymes and Inflammatory Cytokines. Harvested cells were extracted total proteins; then, cellular malondialdehyde (MDA), superoxide dismutase (SOD), lactic dehydrogenase (LDH), glutathione peroxidase (GSH-PX), interleukin-6 (IL-6), tumor necrosis factor alpha (TNF- $\alpha$ ), cysteine-rich intestinal protein 1 (CRIP1), cysteine-rich intestinal protein 2 (CRIP2), and metallothionein 1A (MT1A) activities or levels were determined using ELISA kits (Wuhan Huamei Biotechnology Co. LTD) in accordance with the manufacturer's protocols. 
2.5. Cell Apoptosis Assay. Apoptosis analysis was performed with the Annexin V-FITC/PI (propidium iodide) flow cytometry kit. IPEC-J2 cells were seeded into 6-well plates at a density of $1 \times 10^{6}$ cells/well. After treatment, $5 \mu \mathrm{L}$ Annexin V-FITC for $15 \mathrm{~min}$ and $5 \mu \mathrm{L}$ PI for $5 \mathrm{~min}$ at room according to the manufacturer's instructions [26].

2.6. Cell Cycle Assay. Cell cycle progression was examined with a flow cytometer using propidium iodide (PI) staining. Briefly, IPEC-J2 cells were seeded into 6-well culture plates. After treatment, the cells were trypsinized and fixed with cold $70 \%$ ethanol at $4^{\circ} \mathrm{C}$ overnight. The cells were then rehydrated, washed twice with ice-cold PBS, and analyzed by PI staining. PI absorbance was determined by fluorescence-activated cell sorting on a flow cytometer (Beckman Coulter Inc., USA).

2.7. Mitochondrial ROS Measurement. Intracellular mitochondrial reactive oxygen (ROS) generation was evaluated using MitoSOX Red reagent (Invitrogen, Shanghai, China). IPEC-J2 cells were seeded into 6-well plates and then cultured in different treatments. Cells were treated with $5 \mu \mathrm{M}$ MitoSOX Red reagent at $37^{\circ} \mathrm{C}$ for $10 \mathrm{~min}$ in the dark. Then, the fluorescence intensity of 12,000 cells was assayed using a Beckman MoFlo XDP flow cytometer (Beckman Coulter Inc., CA, USA).

2.8. Mitochondrial Membrane Potential (MMP) Measurement. Mitochondrial depolarization in the early stages of apoptosis was evaluated using JC-1 reagent (Invitrogen) by double fluorescence staining. The loss of MMP was indicated by a decrease in the red/green mean fluorescence intensity ratio. IPEC-J2 cells were seeded into confocal dishes and then treated under different conditions. JC- $1(10 \mu \mathrm{g} / \mathrm{mL})$ was added to the medium for $30 \mathrm{~min}$ in the dark and then the cells were washed twice with PBS. Cells in the confocal dishes were treated with an antifluorescence quenching agent and observed using a Zeiss LSM880 confocal microscope as previously described [26].

2.9. Mitochondrial Respiration Metabolism Assays. Mitochondrial respiration was measured using the XF-24 Extracellular Flux Analyzer and a Cell Mito Stress Test Kit (Agilent Technologies, Inc., CA, USA) in accordance with the manufacturer's instructions. Non-ATP-linked oxygen consumption (proton leak), ATP-linked mitochondrial oxygen consumption (ATP production), and maximal respiration capacity were estimated. Baseline oxygen consumption rate (OCR) minus the maximal respiratory capacity represented the spare respiratory capacity. Residual oxygen consumption after the addition of rotenone and antimycin A was due to nonmitochondrial respiration and was subtracted from all measured values in the analysis. Total cellular protein concentration was determined with a BCA assay kit to normalize mitochondrial respiration rates [27].

2.10. Real-Time Quantitative Polymerase Chain Reaction. The expression of mRNA was measured by real-time quantitative PCR. Total RNA was extracted from samples of IPECJ2 cells using TRIzol reagent (Invitrogen) and reverse transcribed into cDNA using the Prime Script RT reagent kit
(TaKaRa Bio, Otsu, Japan). Quantitative PCR was performed using SYBR Premix Ex Taq (TaKaRa Bio, Japan). The reaction was performed at a total volume of $10 \mu \mathrm{L}$, with the assay solution containing $5 \mu \mathrm{L}$ SYBR Green mix (TaKaRa Bio, Japan), $0.2 \mu \mathrm{L}$ ROX internal reference dye, $3.4 \mu \mathrm{L}$ deionized $\mathrm{H}_{2} \mathrm{O}, 1 \mu \mathrm{L}$ cDNA template, and $0.2 \mu \mathrm{L}$ each of the forward and reverse primers. The expression of the housekeeping gene $\beta$-actin was used to normalize the expression levels. The primers were designed to flank introns using the Primer 5 software. The primer sequences are listed in the supplemental Table 1.

2.11. Protein Qualification by the Wes Simple Western System and Western Blot. The process of protein quantification was performed using the Wes Simple Western System (ProteinSimple, San Jose, CA, USA) or the Western Blot technique as previous described $[25,26]$. The antibodies used in the study included nuclear factor erythroid 2-related factor 2 (Nrf2) (Abcam, Cambridge, MA, USA), $\beta$-actin (Abcam), Kelch-like ECH-associated protein 1 (Keap1) (Abcam), AMP-activated protein kinase (AMPK) (Abcam), phosphorylated AMPK (Abcam), lamin B (Abcam), and p62 (Abcam). The mouse $\beta$-actin antibody was used as a loading control for total protein, while nuclear Nrf2 protein expression was normalized to lamin B. All protein concentrations were determined using a standard BCA protein assay. Results of Wes Simple Western System were obtained using the "gel view" function of the Protein Simple software (ProteinSimple). Western blot data were quantified using the ImageJ software.

2.12. Immunofluorescence Assay. IPEC-J2 cells $\left(1 \times 10^{5}\right.$ cells per well) were seeded into confocal dishes and treated with different conditions. Cells were fixed with $4 \%$ paraformaldehyde for $20 \mathrm{~min}$ and permeabilized with Triton X-100 (0.3\%) for $10 \mathrm{~min}$. Then, cells were blocked with bovine serum albu$\min (1 \%)$ for $30 \mathrm{~min}$ and were incubated overnight with Nrf2, caspase-3, or Keap1 antibodies diluted at 1:100 at $4^{\circ} \mathrm{C}$. Cells were washed with cold PBS three times, and then incubated with secondary antibody for $1 \mathrm{~h}$. Nuclear DNA was labeled with 4',6-diamidino-2-phenylindole (DAPI) for 2 minutes. The fluorescence images were captured using a Zeiss LSM880 confocal microscope and analyzed with the ZEN software.

2.13. Statistical Analysis. Statistical analysis was analyzed through one-way ANOVA or $t$-test using the SPSS 19.0 software. All the data were presented as means \pm standard error of the mean (SEM). $P$ values below 0.05 were considered statistically significant.

\section{Results}

3.1. Effects of ZnLA Supplementation on Cell Viability, Cell Cycle, and Apoptosis. To determine the effects of different $\mathrm{Zn}$ sources on cell proliferation in IPEC-J2 cells, we exposed IPEC-J2 cells to increasing concentrations of $\mathrm{ZnLA}$ or $\mathrm{ZnSO}_{4}$ for $6,12,24,3648$, or $60 \mathrm{~h}$, respectively (Figures 1 (a) and $1(\mathrm{~b})$ ). We found that exposure to $7.5 \mathrm{mg} / \mathrm{L} \mathrm{Zn}$ for $12 \mathrm{~h}$ significantly increased cell viability compared with other treatments $(P<0.05)$. Thus, the concentrations of $7.5 \mathrm{mg} / \mathrm{L} \mathrm{Zn}$ 


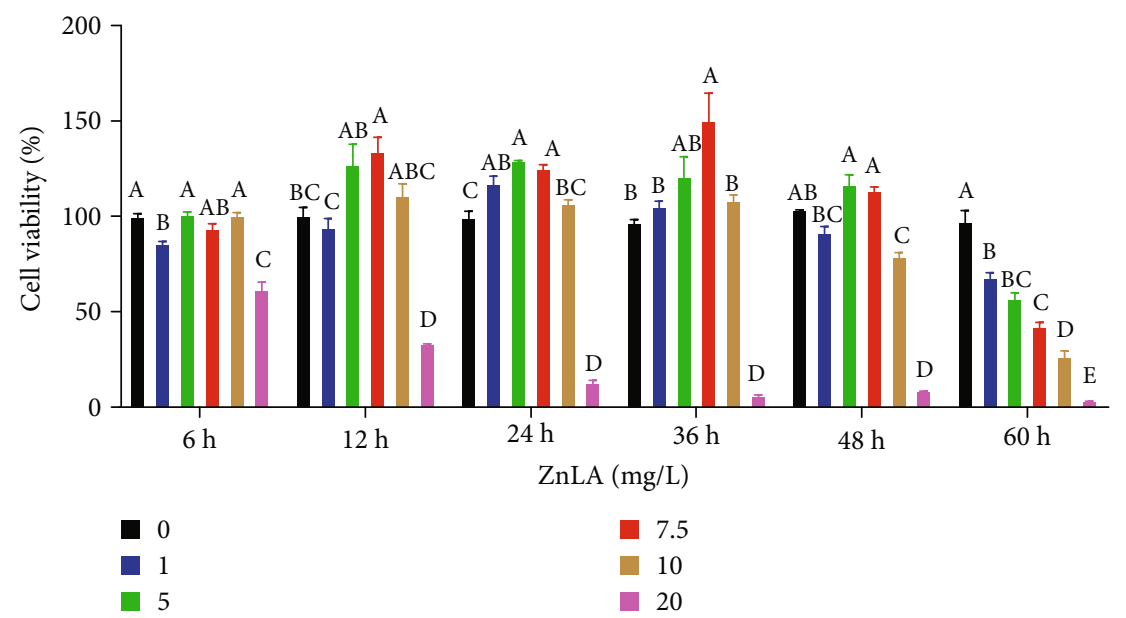

(a)

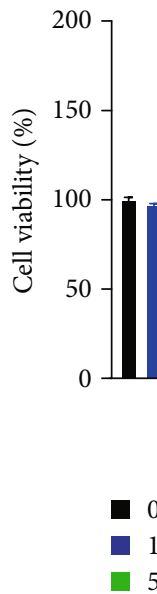

$\begin{array}{ll}\square & 0 \\ \square & 1 \\ & 5\end{array}$

7.5

- 10

- 20

(b)
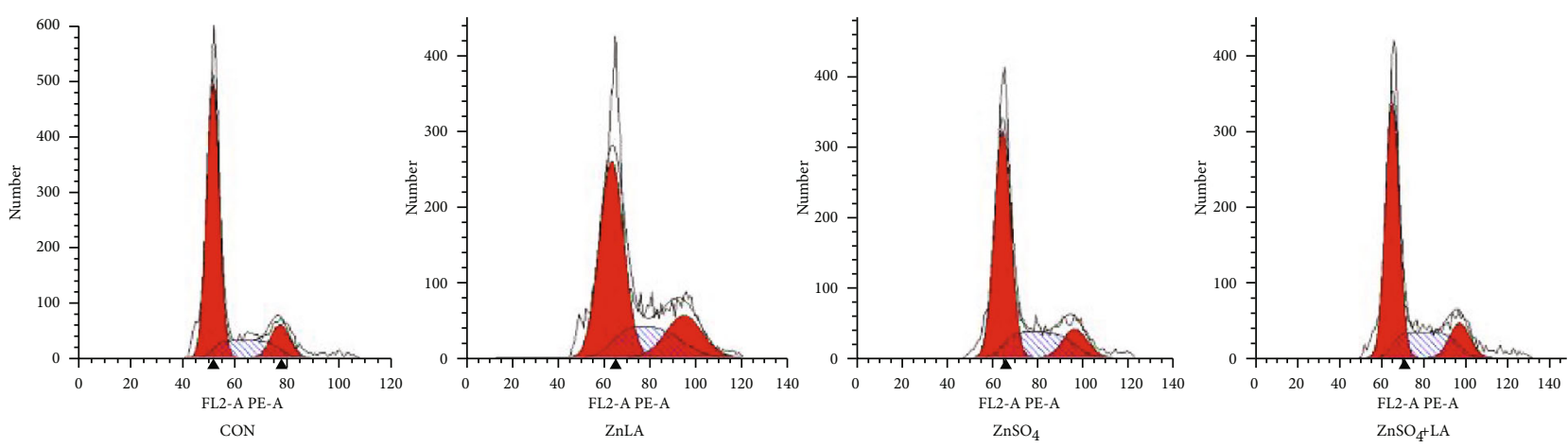

$\square$ Dip G2

$\mathbb{N}$ Dip $S$

(c)

FIgURE 1: Continued. 
G1

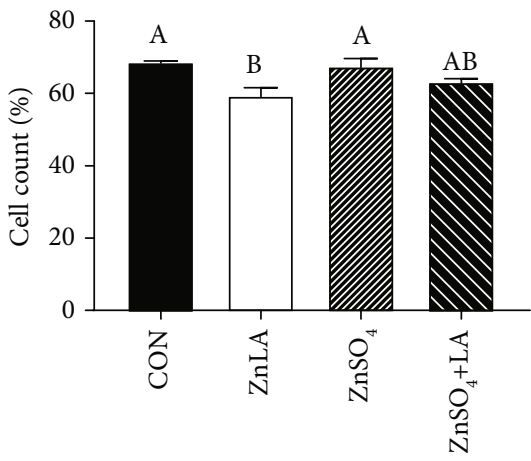

G2

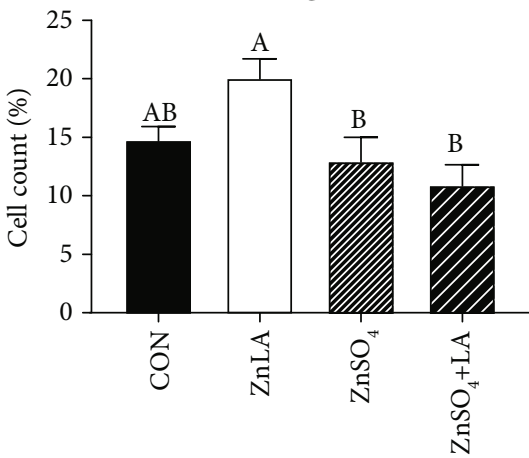

(d)

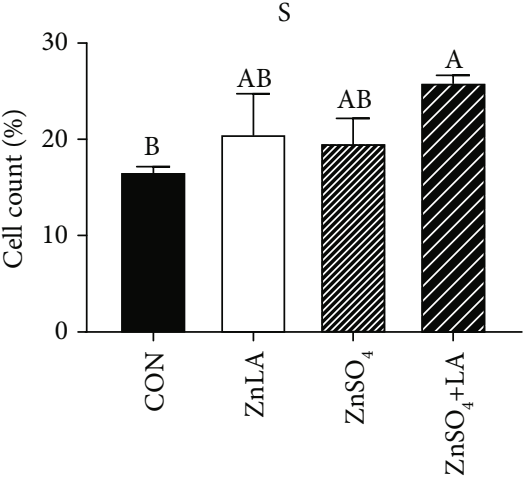

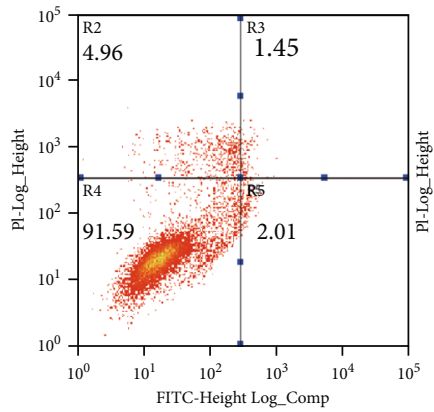

CON

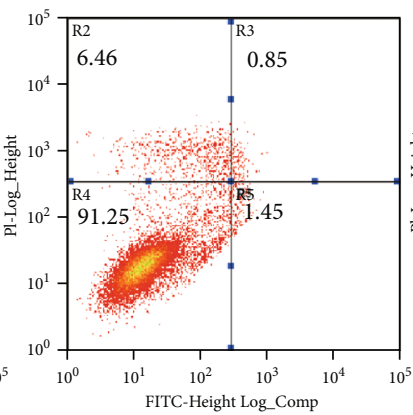

ZnLA

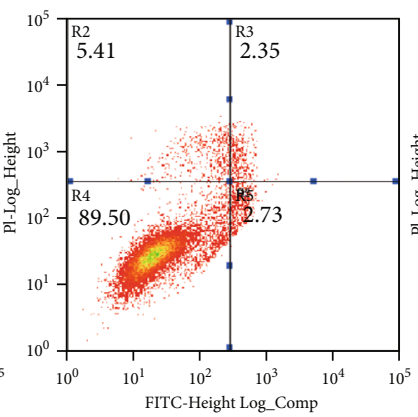

$\mathrm{ZnSO} 4$

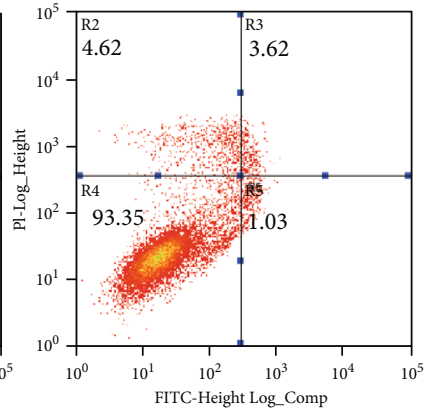

ZnSO4+LA

(e)

FIGURE 1: Effects of zinc lactate on cell viability, cell cycle, and apoptosis in IPEC-J2 cells. Values are expressed as means \pm SEM $(n=4)$. (a, b) Cell viability under different levels of $\mathrm{Zn}$ sources; (c, d) cell cycle in each phase; (e) cell apoptosis ratio. ${ }^{\mathrm{a}, \mathrm{b}, \mathrm{c}}$ Means of bars with different letters were significantly different $(P<0.05)$.

from $\mathrm{ZnLA}$ or $\mathrm{ZnSO}_{4}$ for $12 \mathrm{~h}$ were selected as suitable conditions for the subsequent experiments. As shown in Figures 1(c) and 1(d), the G1 phase of the cell cycle was markedly decreased in the ZnLA group compared with the control group $(P<0.05)$. However, ZnLA administration was increased in the $S$ phase $(P<0.05)$ and $G 2 / M$ phase $(P<0.05)$. In addition, we found that the proportion of early and late apoptotic cells treated with ZnLA was the lowest compared to the other three groups (Figure 1(e)). These results suggested that ZnLA could reduce cell apoptosis and promote cell proliferation.

3.2. Effects of ZnLA Supplementation on Mitochondrial ROS, $M M P$, and Mitochondrial Respiration Metabolism. Our results showed that $\mathrm{Zn}$ treatment decreased the levels of mitochondrial ROS production $(P<0.05)$ but did not differ between the ZnLA and $\mathrm{ZnSO}_{4}$ groups (Figures 2(a) and $2(\mathrm{~b})$ ). There was no difference in the ratio of JC-1 red fluorescence to green fluorescence $(P>0.05)$ (Figure 2(n)). Compared with the control group, ZnLA treatment remarkably increased the mitochondrial basal OCR, nonmitochondrial respiratory capacity, and proton leak $(P<0.05)$ (Figures 2(c)-2(i)). Compared with the $\mathrm{ZnSO}_{4}$ group, ZnLA administration increased the mitochondrial basal OCR, nonmitochondrial respiratory capacity, and maximal respiration in IPEC-J2 cells $(P<0.05)$. $\mathrm{ZnSO}_{4}+\mathrm{LA}$ administration increased the basal OCR rate, ATP production, and maximal respiration compared with the $\mathrm{ZnSO}_{4}$ group $(P<0.05)$. As for mitochondrial-related gene expression, ZnLA supplementation increased the mRNA expression of uncoupling protein 2 (UCP2) and pyruvate dehydrogenase A1 (PDHA1) (Figures 2(j) and 2(m)) compared with the control group, but the mRNA expression of mitochondrial transcription factor A (Tfam) and cytochrome c oxidase (Cycs) was not affected by ZnLA administration (Figures 2(k) and 2(l)). Meanwhile, $\mathrm{ZnSO}_{4}$ treatment increased UCP2 mRNA abundance but did not affect the expression of Tfam, Cycs, and PDHA1.

\subsection{Effects of ZnLA Supplementation on Antioxidant} Function, Inflammation, and $\mathrm{Zn}$ Transport. For critical validation of the in vitro experiment demonstrating the effects of ZnLA on intestinal Zn transport, inflammation, and antioxidant function, we determined the levels or activities of intracellular antioxidant enzymes, inflammatory cytokines, and zinc transporter proteins (Figures 3(a)-3(i)). Compared with the control group, $\mathrm{LDH}$ activity was decreased with ZnLA or $\mathrm{ZnSO}_{4}$ treatment $(P<0.05)$, and the activity of $\mathrm{LDH}$ in the ZnLA treatment was lower than that in $\mathrm{ZnSO}_{4}$ treatment. Compared with the control group, ZnLA treatment significantly increased the activity of GSH-PX $(P<0.05)$, while decreasing the MDA concentration $(P>0.05)$. SOD activity in the $\mathrm{ZnSO}_{4}+\mathrm{LA}$ group was the lowest $(P<0.05)$. Compared with the control group, the concentration of intracellular IL- 6 in the other three treatments was significantly decreased $(P<0.05)$, but there was no difference in TNF- $\alpha$ concentration among these groups. ZnLA 


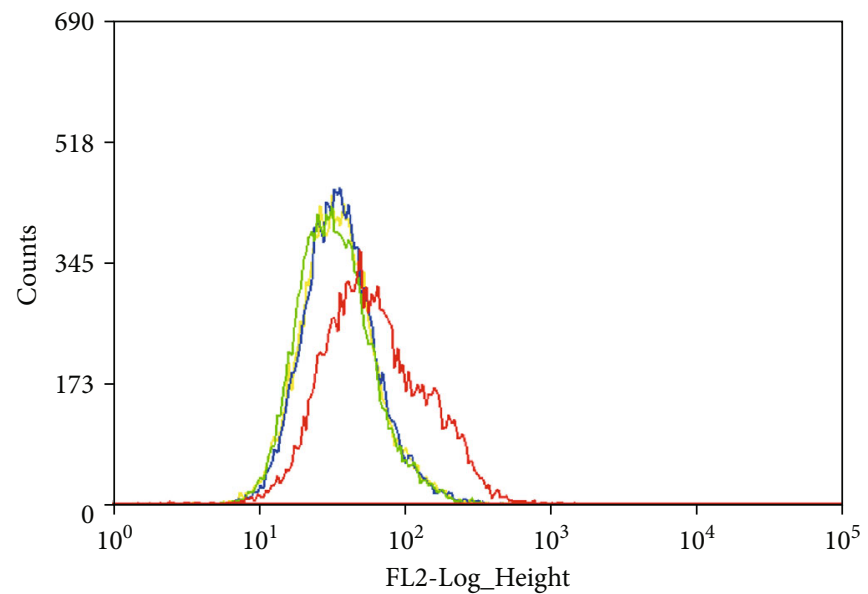

(a)
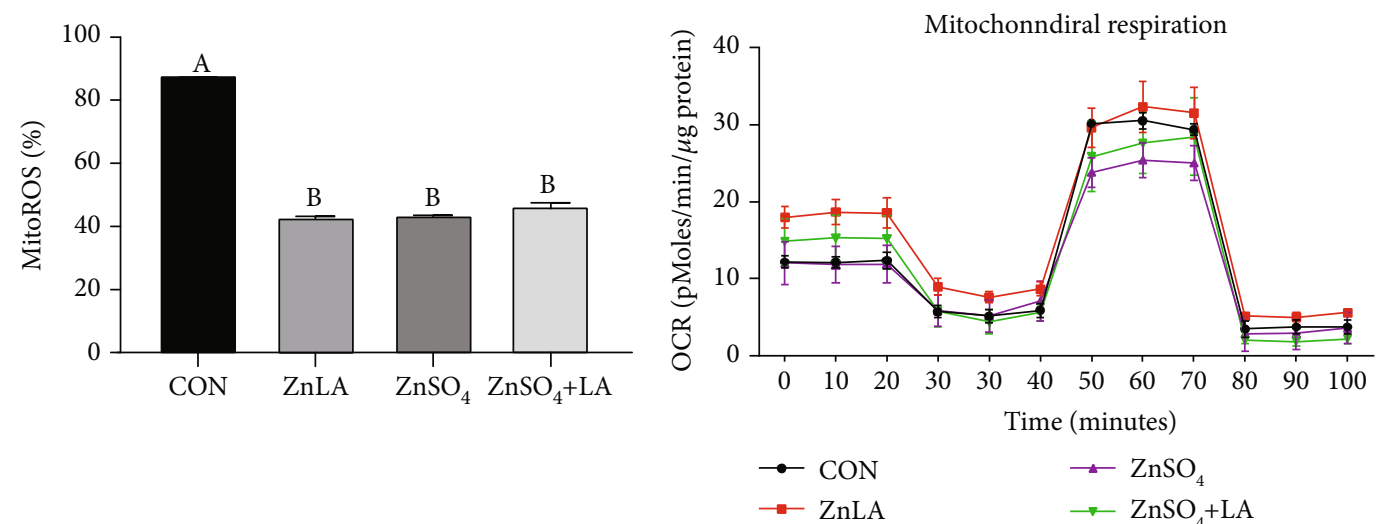

(b)

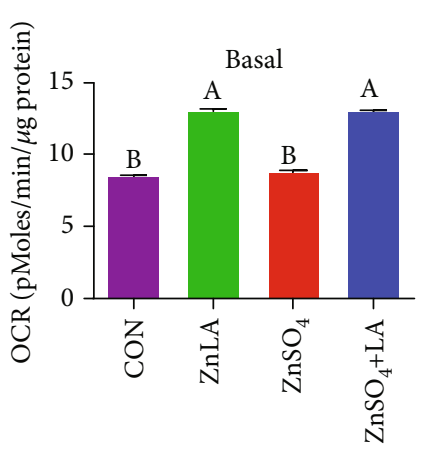

(d)

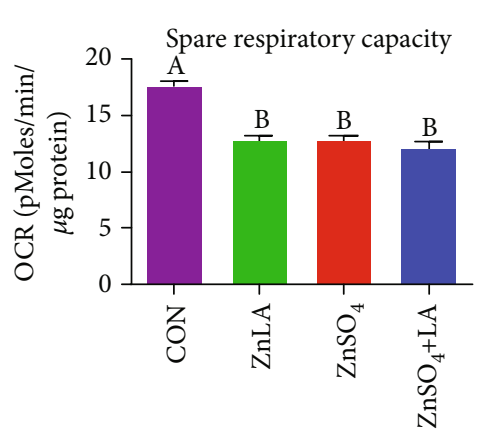

(g)

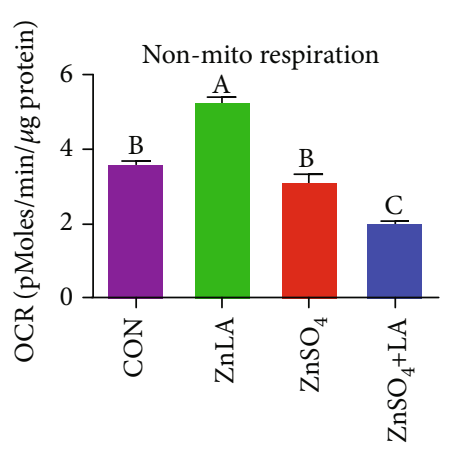

(e)

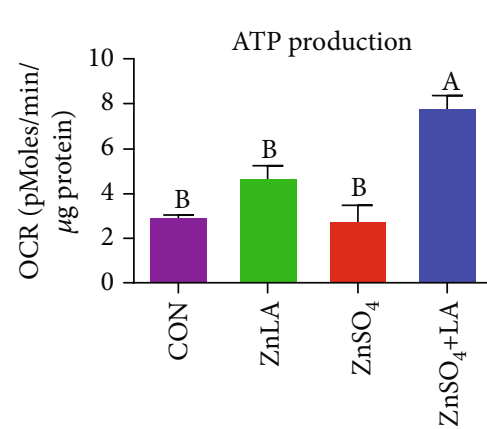

(h) (c)

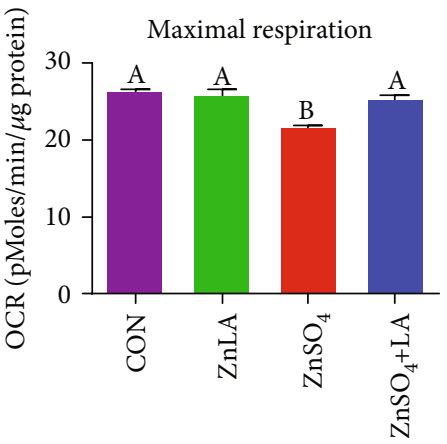

(f)

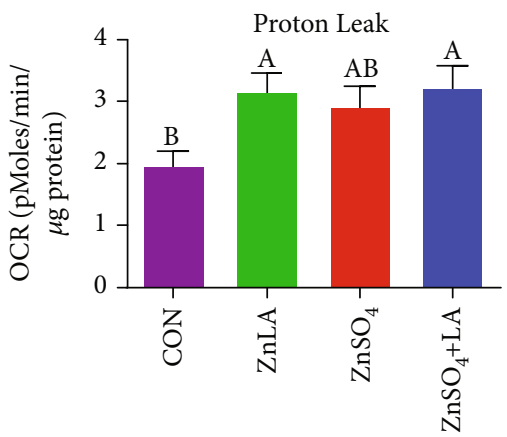

(i)

Figure 2: Continued. 


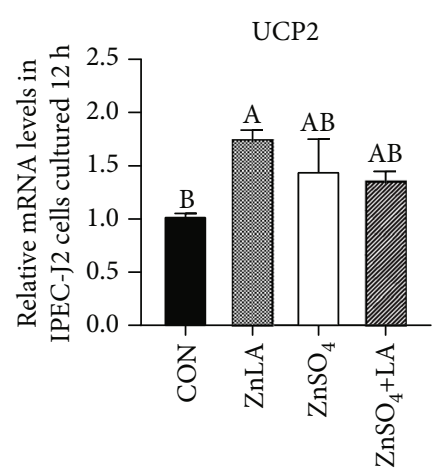

(j)

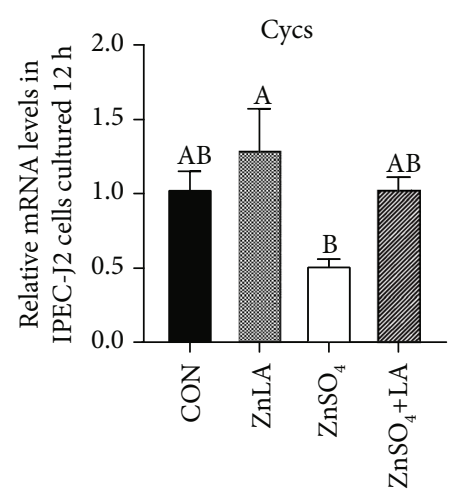

(1)

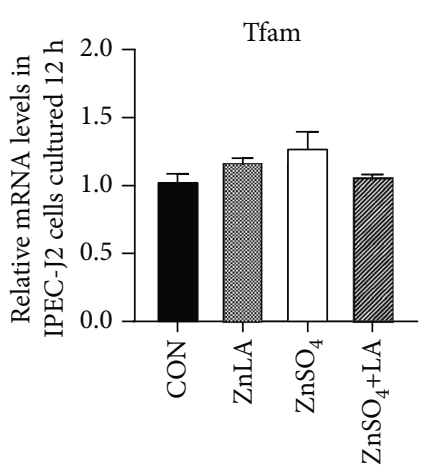

$(\mathrm{k})$

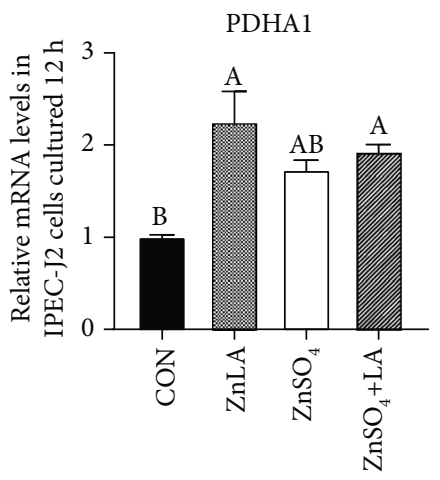

$(\mathrm{m})$
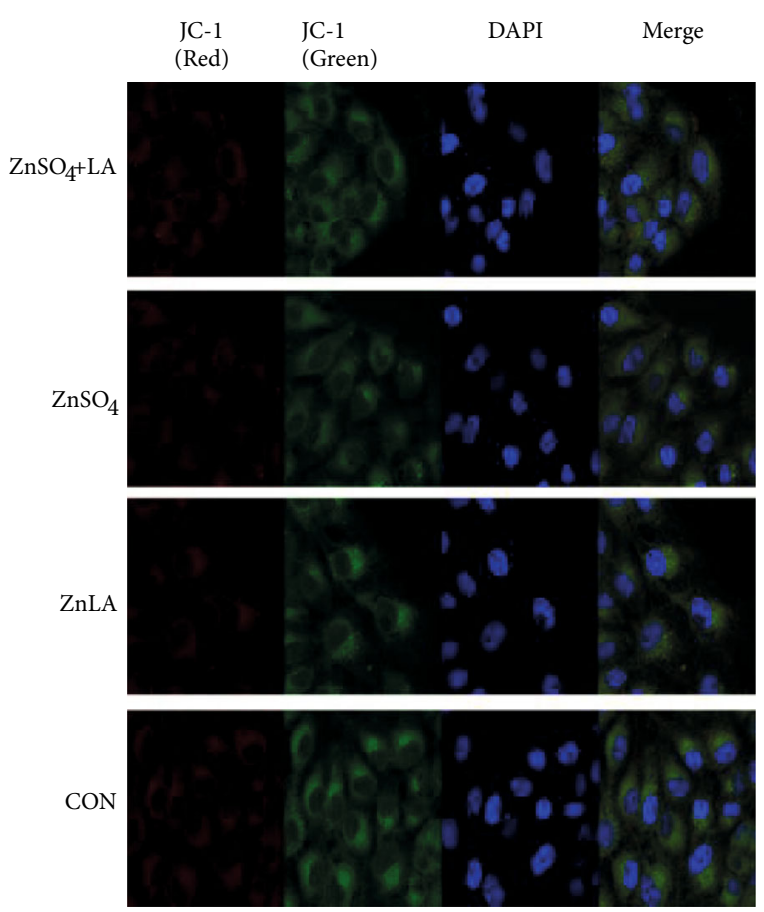

(n)

FIGURE 2: Effect of zinc lactate on mitochondrial ROS, mitochondrial membrane potential, and cellular respiration metabolism in IPEC-J2 cells. Values are expressed as means \pm SEM $(n=4)$. (a, b) Mitochondrial ROS level: red line, CON; green line, $\mathrm{ZnLA}$; blue line, $\mathrm{ZnSO}$; yellow line, $\mathrm{ZnSO}_{4}+\mathrm{LA}$; (c) oxygen consumption rate; (d) basal respiration; (e) non-mito respiratory; (f) maximal respiration; (g) spare respiratory; (h) ATP production; (i) proton leak; (j) the relative expression of UCP2; $(\mathrm{k}$ ) the relative expression of Tfam; (l) the relative expression of Cycs; $(\mathrm{m})$ the relative expression of PDHA1; (n) mitochondrial membrane potential: red, aggregate; green, monomer. a,b,c Means of bars with different letters were significantly different $(P<0.05)$.

supplementation increased the levels of $\mathrm{Zn}$ transporter proteins CRIP1 and CRIP2 $(P<0.05)$, but had no effect on MT1A levels compared with that in the CON group. Furthermore, we also determined the mRNA expression levels of $\mathrm{Zn}$ transporters and antioxidant-related genes (Figures 3(j)$3(q))$. Compared with the control group, $\mathrm{ZnLA}$ or $\mathrm{ZnSO}_{4}$ supplementation markedly increased the mRNA expression of ZNT- 1 and MT-2B in IPEC-J2 cells $(P<0.05)$. The mRNA expression of CRIP2 and MT1A in the $\mathrm{ZnSO}_{4}$ group was also increased in comparison with the other three groups $(P<0.05)$, while there was no difference in the expression of CRIP1 among the four groups. The mRNA expression levels of CAT and CuZnSOD in the ZnLA group were higher than those in the other groups, but there was no difference in the expression of Gpxl among these groups.

3.4. Effects of ZnLA Supplementation on the Expression of Nrf2/Keap1, AMPK, and Autophagy-Related Pathways. To further validate whether ZnLA supplementation could alleviate oxidative stress in IPEC-J2 cells via Nrf2/Keap1, AMPK, and autophagy-related pathways, we determined the expression of the key target molecules using Western blotting and immunofluorescence techniques. We found that Nrf2 protein was mostly located in the cytoplasm of IPEC-J2 cells, but $\mathrm{ZnLA}$ administration could increase the amount of
Nrf2 transferred to the nucleus (Figures 4(a) and 4(c)). Compared with the control group, the expression of Keap1 was reduced by ZnLA treatment $(P<0.05)$. Furthermore, the protein expression of AMPK in $\mathrm{ZnSO}_{4}+\mathrm{LA}$ group was highest $(P<0.05)$, and ZnLA treatment remarkably increased $(P<0.05)$ the protein expression of phosphorylated AMPK (Figures 4(c) and 4(d)). Compared with the $\mathrm{ZnSO}_{4}$ group, the expression of p62 in the ZnLA group was decreased, but there was no significant difference (Figure 4(e)). Our results also showed that ZnLA treatment markedly reduced the mRNA expression of autophagy-related genes LC3B-1 and Beclin $(P<0.05)$, but it had no effect on the mRNA expression of p62 and LC3B-2 $(P>0.05)$ (Figure 4(f)).

3.5. Effects of ZnLA Supplementation on Mitochondrial ROS, Apoptosis, and the AMPK-Nrf2-p62-Mediated Pathway under Oxidative Stress Conditions. To further define the effect of ZnLA on the alleviation of oxidative stress in enterocytes, we built an oxidative stress model of $\mathrm{H}_{2} \mathrm{O}_{2}$-induced IPEC-J2 cells. The levels of mitochondrial ROS and apoptosis were determined in the presence or absence of $7.5 \mathrm{mg} / \mathrm{L}$ ZnLA. As shown in Figure 5(a), $\mathrm{H}_{2} \mathrm{O}_{2}$ exposure markedly increased cell apoptosis in IPEC-J2 cells, while ZnLA supplementation decreased the proportion of apoptotic cells (the proportion of early apoptotic cells and late apoptotic cells, 


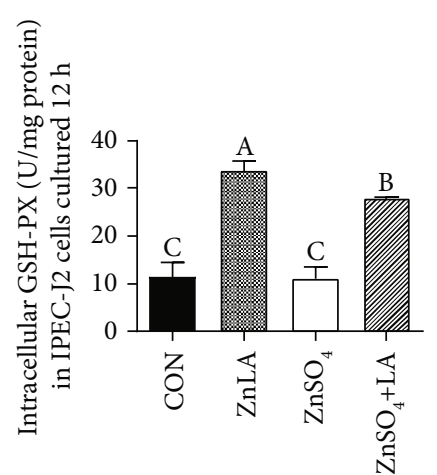

(a)
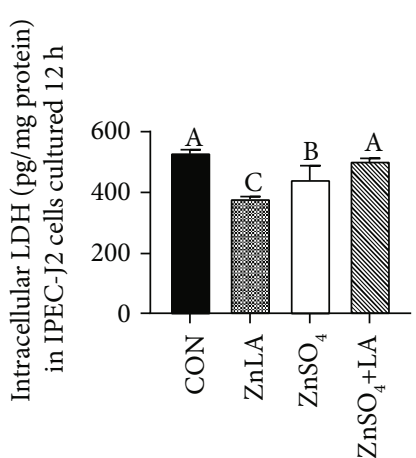

(b)

(e)

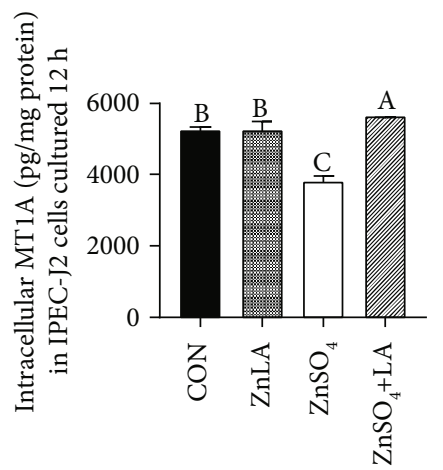

(i)

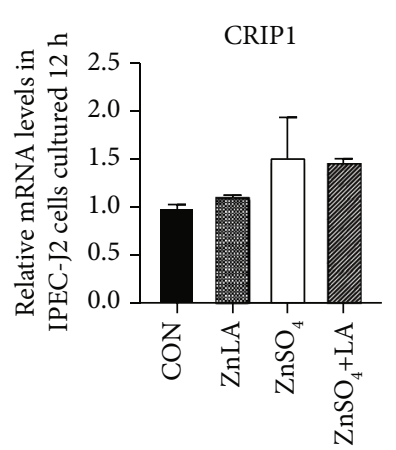

(m)

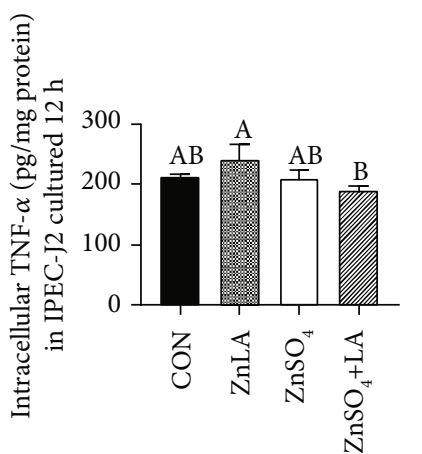

(f)

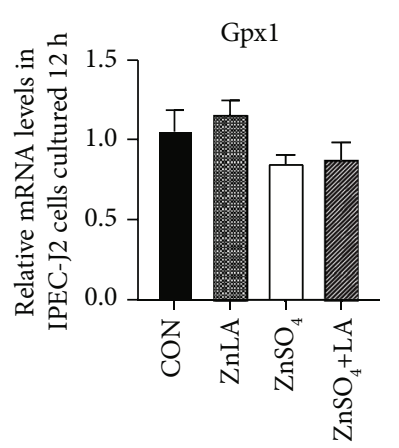

(j)

(n)

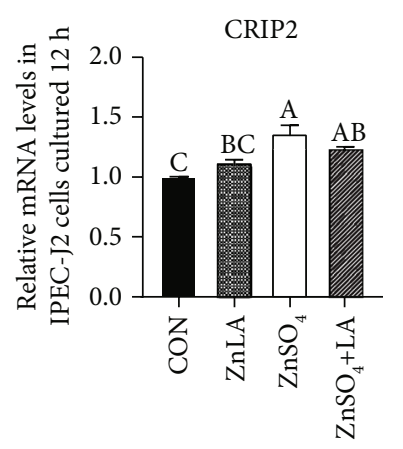

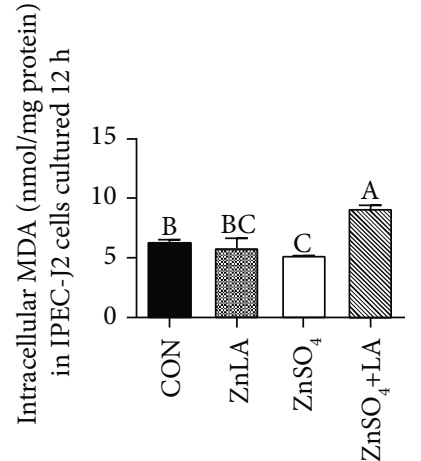

(c)

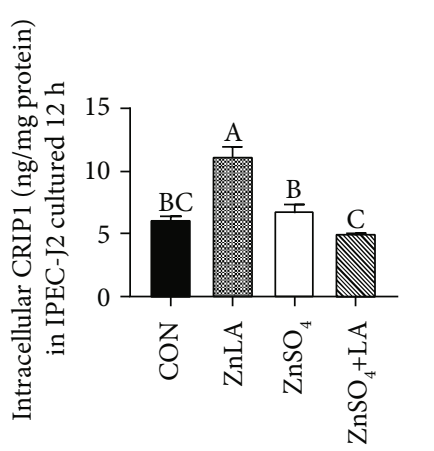

(g)

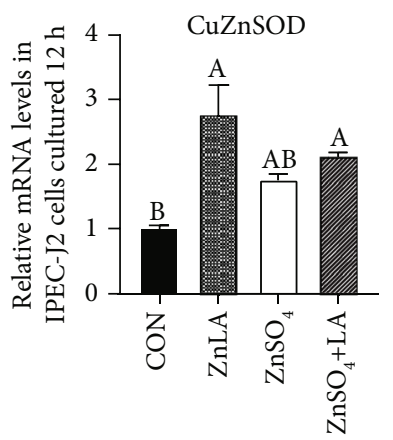

(k)

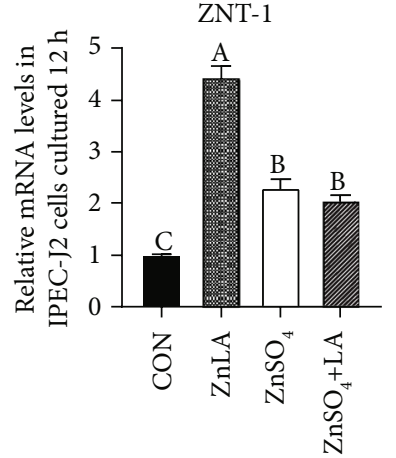

(o)

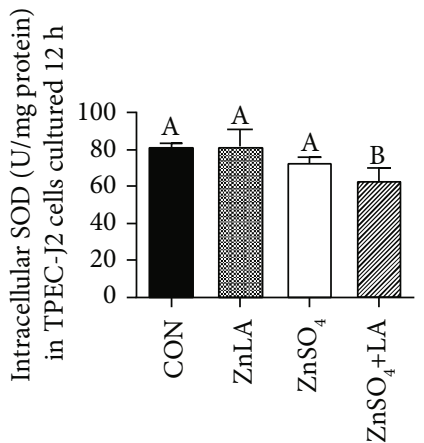

(d)

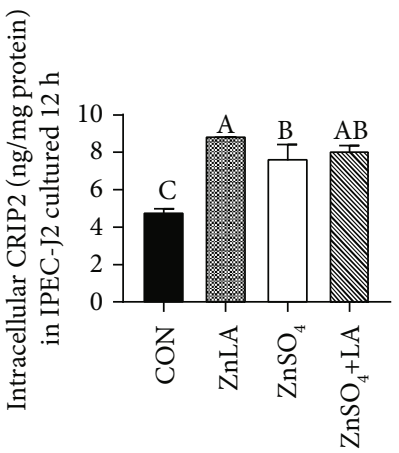

(h)

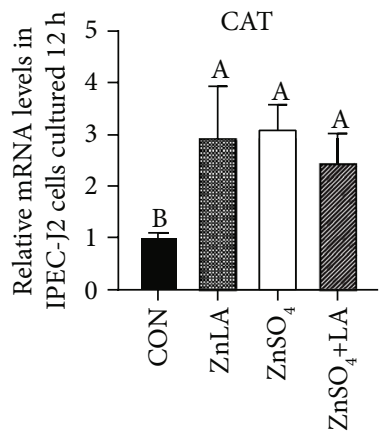

(l)

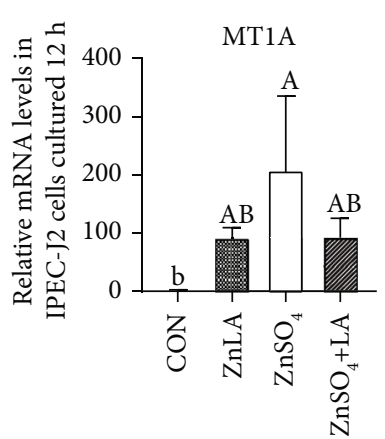

(p)

Figure 3: Continued. 


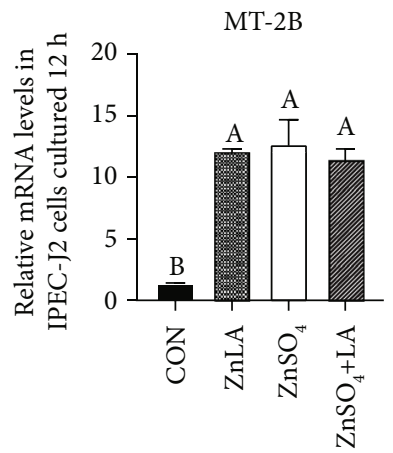

(q)

Figure 3: Effect of zinc lactate on Zn transport, inflammatory cytokines, and antioxidant enzymes in IPEC-J2 cells. Values are expressed as means \pm SEM $(n=4)$. (a) The activity of GSH-PX; (b) the concentration of LDH; (c) the concentration of MDA; (d) the activity of SOD; (e, f) the concentration of IL- 6 and TNF- $\alpha$; (g-i) the concentration of CRIP1, CRIP2, and MT1A; $(j-q)$ the mRNA expression of Gpx1, CuZnSOD, CAT, CRIP1, CRIP2, ZNT-1, MT1A, and MT-2B. ${ }^{\mathrm{a}, \mathrm{b}, \mathrm{c}}$ Means of bars with different letters were significantly different $(P<0.05)$.

$6.84 \%)$ compared with the $\mathrm{H}_{2} \mathrm{O}_{2}$ treatment groups (12.24\%) $(P<0.05)$. The results of the immunofluorescence assay showed that caspase- 3 was located in the cytoplasm of IPEC-J2 cells, and compared with the control group, $\mathrm{H}_{2} \mathrm{O}_{2}$ exposure significantly increased caspase- 3 protein expression $(P<0.05)$ (Figure $5(\mathrm{~d}))$, while $\mathrm{ZnLA}$ or $\mathrm{ZnSO}_{4}$ administration decreased the protein expression of caspase- 3 .

To test whether ZnLA could protect IPEC-J2 cells from oxidative damage by scavenging intracellular ROS, flow cytometry was used to detect mitochondrial ROS. The results showed that compared with the $\mathrm{H}_{2} \mathrm{O}_{2}$ group, ZnLA treatment significantly decreased mitochondrial ROS production in the $\mathrm{H}_{2} \mathrm{O}_{2}$-induced IPEC-J2 cells $(P<0.05)$ (Figures 5(b) and $5(\mathrm{c})$ ). However, $\mathrm{ZnSO}_{4}$ treatment had no effect on the levels of mitochondrial ROS in $\mathrm{H}_{2} \mathrm{O}_{2}$-induced IPEC-J2 cells $(P>0.05)$. As shown in Figures 5(e) and 5(f), the protein expression of nuclear $\mathrm{Nrf} 2$ in the $\mathrm{ZnLA}+\mathrm{H}_{2} \mathrm{O}_{2}$ group was significantly increased while Keap1 protein expression was decreased compared with the $\mathrm{H}_{2} \mathrm{O}_{2}$ group. $\mathrm{H}_{2} \mathrm{O}_{2}$ treatment increased the expression of autophagy-related protein $\mathrm{p} 62$, while ZnLA supplementation markedly decreased the expression of p62 in $\mathrm{H}_{2} \mathrm{O}_{2}$-induced IPEC-J2 cells $(P<0.05)$ (Figure 5(g)). To further explore whether AMPK-Nrf2 signaling could be activated by ZnLA supplementation under oxidative stress conditions, we treated cells with an AMPK inhibitor (Compound C) to inhibit AMPK activity [28]. When AMPK activity was inhibited by Compound C, ZnLA supplementation did not promote the nuclear translocation of $\mathrm{Nrf} 2$ and did not decrease the protein expression of Nrf2 and Keap 1 in the cytoplasm of IPEC-J2 cells $(P>0.05)$ (Figures 5(h) and 5(i)).

\section{Discussion}

Dietary Zn supplementation could promote cell proliferation and protect intestinal barrier function in postweaning piglets against diarrhea [29]. In the present study, we found that the addition of ZnLA was more effective in promoting cell proliferation and suppressing cell apoptosis than $\mathrm{ZnSO}_{4}$, at the same concentration. This is consistent with many reports that $\mathrm{Zn}$ supplementation plays an important role in improv- ing cell proliferation and differentiation [30, 31]. For example, a recent study has reported that ZnLA supplementation improved the growth performance of young grass carp by maintaining intestinal immune and physical barrier functions [32]. The small intestine, as a major site of $\mathrm{Zn}$ absorption, can maintain $\mathrm{Zn}$ homeostasis by regulating the expression of $\mathrm{Zn}$ transport proteins [33]. A number of proteins involved in $\mathrm{Zn}$ absorption and transport have also been identified, including metallothionein (MT), SLC30 (ZNT), SLC39 (ZIP), and CRIP [34]. Previous studies reported that downregulation of ZNT-1 protein could cause the release of $\mathrm{LDH}$ and the activation of caspase protein following ischemia-reperfusion [35]. MT participates in the storage, transport, and bioutilization of $\mathrm{Zn}$, so a decreased expression of MT reduces the absorption efficiency of $\mathrm{Zn}$ in the body [36]. Moreover, MT2 is rich in reduced thiol groups ( $\mathrm{SH}$ ), which have a free radical scavenging capacity 100 times that of GSH, and can inhibit the release of mitochondrial cytochrome $c$ and activate caspase- 3 to reduce cell apoptosis and myocardial injury $[37,38]$. These were further confirmed by the present study where it was found that ZnLA administration increased the mRNA expression of ZNT-1, MT1A, and MT-2B and intracellular GSH-PX activity, but decreased LDH activity, cell apoptosis, and caspase- 3 protein expression levels in IPEC-J2 cells. Further, CRIP and MT regulate physiological balance by competitive transport of $\mathrm{Zn}$ [39]. In the current study, we found that ZnLA supplementation promoted the protein expression of CRIP1/2 in IPEC-J2 cells, suggesting the improvement of $\mathrm{Zn}$ transport capacity following ZnLA treatment. The results of cell apoptosis and caspase protein expression also indicated that the antiapoptosis effect of $\mathrm{ZnLA}$ was better than that of $\mathrm{ZnSO}_{4}$ in IPEC-J2 cells.

Mitochondria, a site for the major source of intracellular ATP, plays a crucial role in scavenging ROS and is tightly linked to apoptosis and proliferation [40, 41]. Our results showed that ZnLA treatment increased the mRNA expression of PDHA1 and UCP2 in IPEC-J2 cells. PDHA1 can regulate mitochondrial ATP production and control the generation of ROS [42]. This is consistent with the results of present study that ZnLA treatment increased mitochondrial ATP production and decreased the production of 


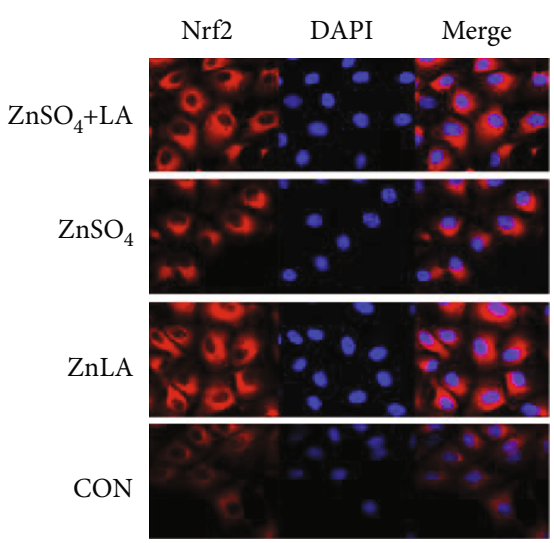

(a)
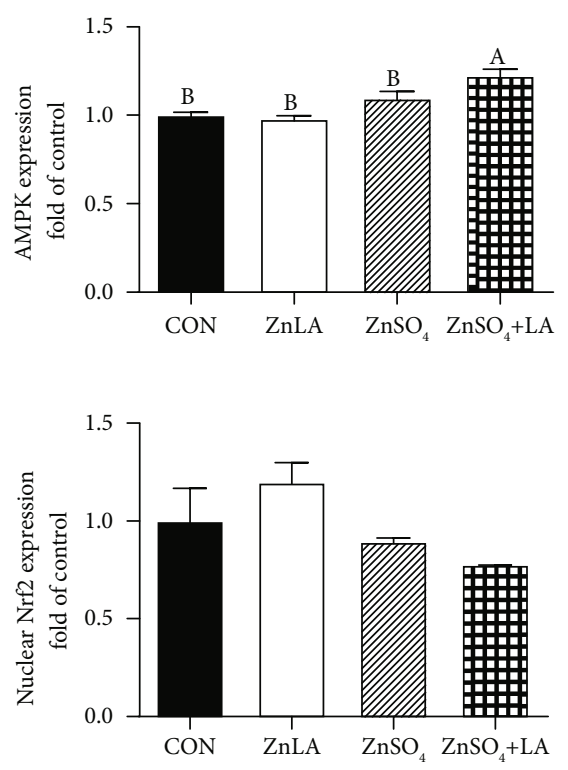

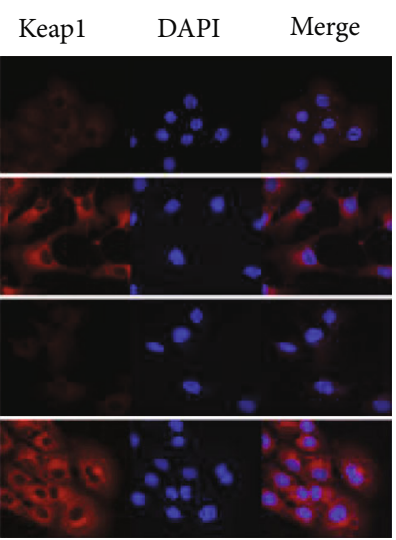

(b)
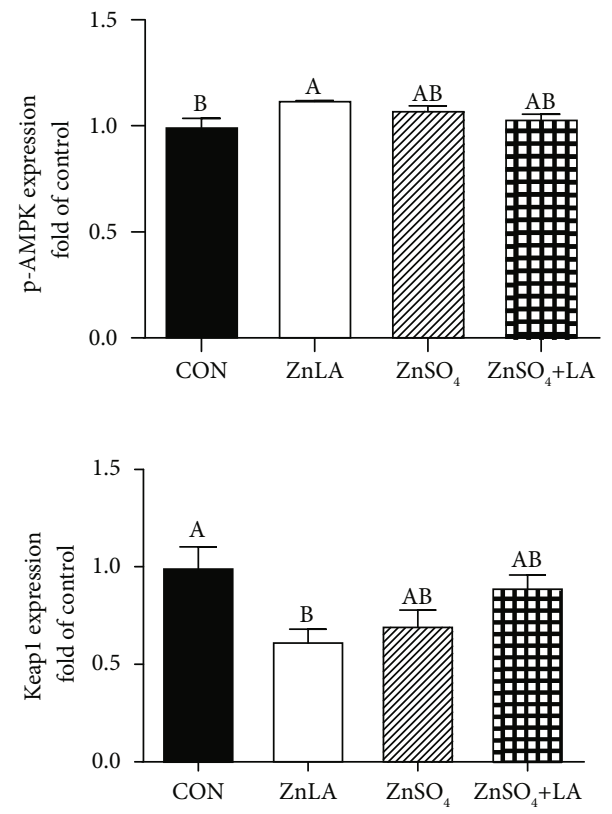

(d)

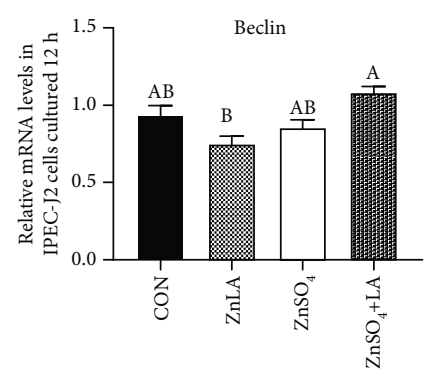

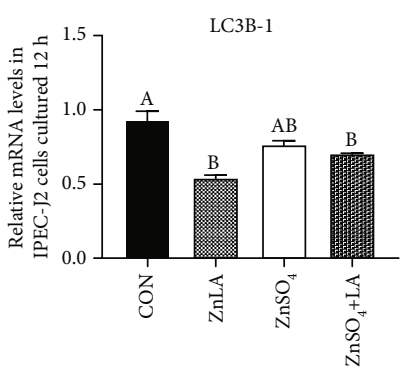

(f)

(e)

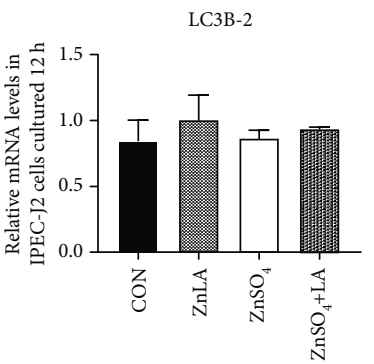

FIGURE 4: Effects of zinc lactate on the AMPK-Nrf2-p62 signaling pathway in IPEC-J2 cells. Values are expressed as means \pm SEM ( $n=4)$. (a) Localization of Nrf2 (×63 magnification): red, Nrf2; blue, DAPI; (b) localization of Keap1 (×63 magnification): red, Keap1; blue, DAPI; (c, d) protein expression of AMPK-Nrf2 pathway; (e) p62 protein expression; (f) the mRNA expression of Beclin, p62, LC3B-1, and LC3B-2. a,b,c Means of bars with different letters were significantly different $(P<0.05)$.

mitochondrial ROS. UCP2, a protein on the inner membrane of mitochondria, can inhibit mitochondrial membrane transport pore opening, prevent mitochondrial $\mathrm{Ca}^{2+}$ overload, and reduce the formation of ROS, thereby inhibiting cell apoptosis [43]. Diano and Horvath reported that UCP2 activation could increase proton leak and then decreased ROS production to defend against oxidative stress [44]. Based on the detection of cell respiration, we also observed that ZnLA administration increased mitochondrial proton leakage, mitochondrial basal OCR, and nonmitochondrial respiratory 

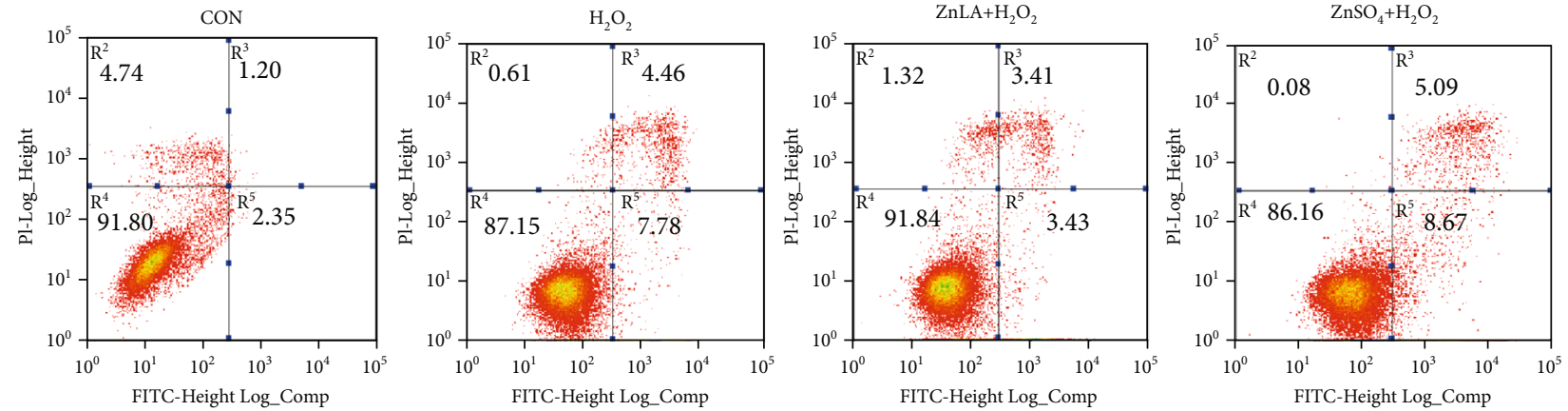

(a)

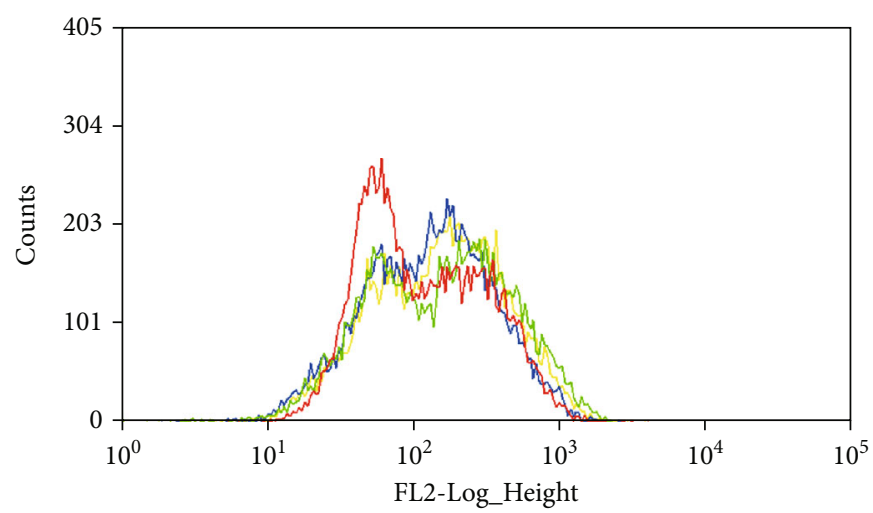

(b)

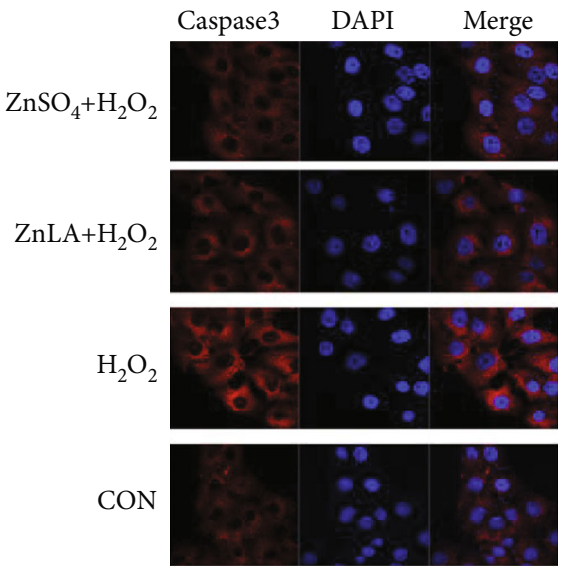

(d)

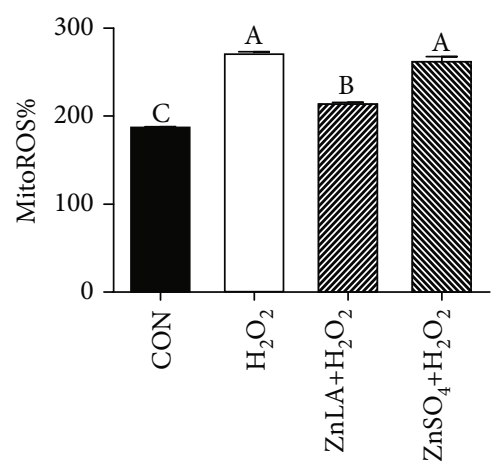

(c)
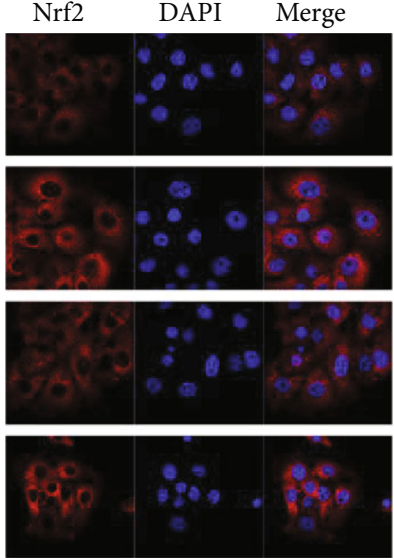

(e)

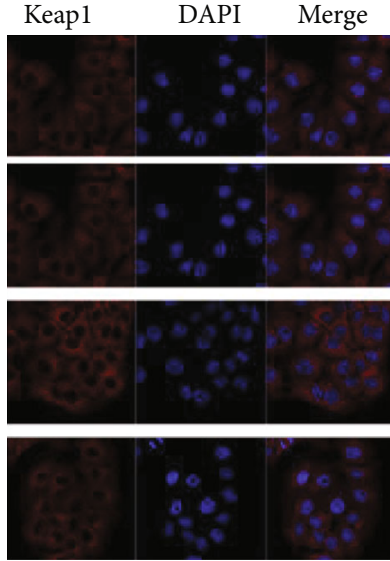

(f)

Figure 5: Continued. 

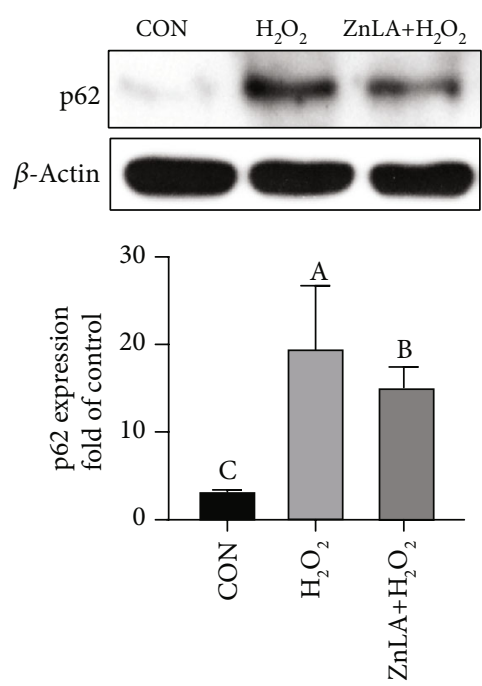

(g)
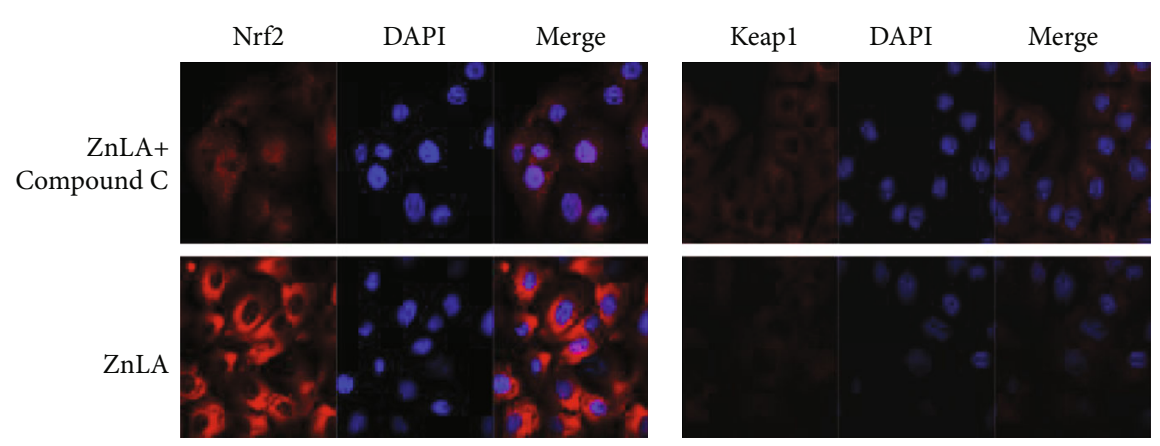

(h) (i)

FIGURE 5: Effects of zinc lactate on cell apoptosis, mitochondrial ROS, and AMPK-Nrf2-p62 signaling pathway in $\mathrm{H}_{2} \mathrm{O}_{2}$-induced IPEC-J2 cells. Values are expressed as means \pm SEM $(n=4)$. (a) Cell apoptosis; $(b, c)$ mitochondrial ROS level: red line, $\mathrm{CON}_{2}$; green line, $\mathrm{H}_{2} \mathrm{O}_{2}$; blue line, $\mathrm{ZnLA}+\mathrm{H}_{2} \mathrm{O}_{2}$; yellow line, $\mathrm{ZnSO}_{4}+\mathrm{H}_{2} \mathrm{O}_{2}$; (d) caspase-3 expression ( $\times 63$ magnification): red, caspase-3; blue, DAPI; (e) localization of Nrf2 ( $\times 63$ magnification): red, Nrf2 or keap1; blue, DAPI; (f) localization of Keap1 ( $\times 63$ magnification); (g) p62 protein expression; (h, i) localization of Nrf2 and Keap1 ( $\times 63$ magnification): red, Nrf2 or keap1; blue, DAPI. ${ }^{\text {a,b,c }}$ Means of bars with different letters were significantly different $(P<0.05)$.

capacity, suggesting that ZnLA could improve mitochondrial respiratory metabolism and maintain energy equilibrium in IPEC-J2 cells. Our current results showed that ZnLA had no effect on MMP. It is known that decreased MMP promoted mitochondrial membrane permeability transition pore opening, activated the caspase-mediated apoptosis pathway, and led to cell apoptosis [45]. Increased MMP inhibited oxidative phosphorylation, resulting in an imbalance of energy metabolism [46]. Our results indicated that ZnLA administration could maintain the homeostasis of MMP. In addition, our results also showed that $\mathrm{ZnSO}_{4}+\mathrm{LA}$ supplementation increased mitochondrial basal OCR, ATP production, and proton leak. This may be because lactic acid forms pyruvate in the presence of $\mathrm{LDH}$, which then enters the mitochondria to participate in energy metabolism, thereby increasing the production of ATP. These results suggest that ZnLA administration plays important roles in mitochondrial function.

Previous studies reported that dietary Zn deficiency resulted in an increased sensitivity to oxidative stress and increased ROS production in animals [47]. This was evidenced by our findings that treatment with ZnLA improved antioxidant capacity in IPEC-J2 cells by regulating antioxidant-related gene expression and antioxidant enzyme concentrations, as well as reducing mitochondrial ROS levels. GSH-PX, CAT, and SOD are important members of the antioxidant enzyme system [48]. In the present study, ZnLA treatment significantly increased the CAT and CuZnSOD mRNA abundance and the activity of GSH-PX in IPEC-J2 cells, indicating that ZnLA administration may enhance their antioxidant ability by improving the expression and activity of antioxidant-related enzymes. Due to alterations in $\mathrm{Zn}$ disposition during the inflammatory response, this makes it even easier to interpret the relationship between $\mathrm{Zn}$ metabolism and immune function in animals [49]. Our results showed that ZnLA administration decreased the secretion of proinflammatory cytokines such as IL-6 and TNF-a in IPEC-J2 cells. This is consistent with a previous study as reported that addition of ZnLA could decrease serum IL-6 concentration of grass carp to improve immunity. Recent reports have proved that $\mathrm{Zn}$ plays a role in maintaining the integrity of the intestinal mucosa through its function in $\mathrm{T}$ cell generation and regulating inflammatory cytokines [50].

It has been reported that antioxidant enzyme activities were partly related to the gene transcription, which were regulated by Nrf2/Keap1 signaling molecules [51]. In the present study, ZnLA administration promoted Nrf2 nuclear translocation and prevented the formation of the Nrf2/Keap1 complex, which resulted in the upregulation of antioxidant gene expression. Bartolini et al. reported that the aggregation of p62 enhanced its interaction with Keap1 and blocked the degradation of Keap1 by autophagosomes, thus activating the translocation of Nrf2 to the nucleus [52]. However, our results showed that under $\mathrm{H}_{2} \mathrm{O}_{2}$ induction conditions, $\mathrm{ZnLA}$ supplementation decreased the expression of p62 and Keap1, while increasing the expression of Nrf2. It is possible that the activated Nrf2 signaling pathway inhibited cell autophagy by scavenging ROS, thereby forming an antioxidative stress feedback pathway. Furthermore, there is another evidence showing that activation of AMPK could alleviate oxidative stress via the crosstalk between Nrf2 and AMPK signals [28]. In our current study, Compound C, an AMPK inhibitor, was used to inhibit the activity of AMPK and to investigate the interaction between Nrf2 and AMPK. Our results showed that under normal conditions, the protein expression of phosphorylated AMPK was increased by ZnLA 
administration, and when the activity of AMPK was inhibited by Compound C, ZnLA treatment still led to a decreased expression of nuclear Nrf2 protein. However, when Compound $\mathrm{C}$ was removed, ZnLA administration could significantly increase the expression of $\mathrm{Nrf} 2$ and decrease p62 protein expression in $\mathrm{H}_{2} \mathrm{O}_{2}$-induced IPEC-J2 cells. These suggest that ZnLA might activate the AMPK-Nrf2-p62 signaling pathway to alleviate oxidative stress in IPEC-J2 cells. Zimmermann et al. showed that the activation of AMPK could facilitate the nuclear translocation of $\mathrm{Nrf} 2$ and improve mitochondrial respiratory metabolism in response to oxidative stress [53]. This is consistent with our current results as showed that ZnLA administration increased the Nrf2 nuclear translocation and AMPK activity as well as cell respiration, thereby promoting the expression of antioxidant-related genes to eliminate excess mitochondrial ROS. These results indicate that exogenous ZnLA may maintain redox balance and mitochondrial function by activating the AMPK-Nrf2p62 signaling pathway in enterocytes.

\section{Conclusions}

This study provided evidence that the administration of ZnLA has a better effect on promoting mitochondrial ROS against oxidative stress, compared to $\mathrm{ZnSO}_{4}$ treatment. Furthermore, ZnLA supplementation enhanced the activities and expression of antioxidant enzymes, decreased proinflammatory cytokine secretion, and modulated mitochondrial function by activating the AMPK-Nrf2-p62 pathway under normal or oxidative stress conditions. The AMPK-Nrf2-p62 pathway activated by ZnLA could further regulate the restoration of redox balance. The in vitro efficacy of ZnLA indicated that it may be used in animal trials for the prevention of oxidative stress. Our novel findings also suggested that $\mathrm{ZnLA}$, as a new feed additive for weaned piglets, has the potential to be an alternative for an equivalent amount of inorganic $\mathrm{Zn}$.

$\begin{array}{ll}\text { Abbreviations } \\ \text { ZnLA: } & \text { Zinc lactate } \\ \text { Zn: } & \text { Zinc } \\ \text { Compound C: } & \text { AMPK inhibitor } \\ \text { MDA: } & \text { Malondialdehyde } \\ \text { SOD: } & \text { Superoxide dismutase } \\ \text { LDH: } & \text { Lactic dehydrogenase } \\ \text { GSH-PX: } & \text { Glutathione peroxidase } \\ \text { ROS: } & \text { Reactive oxygen species } \\ \text { MMP: } & \text { Mitochondrial membrane potential } \\ \text { Nrf2: } & \text { Nuclear factor erythroid 2-related factor 2 } \\ \text { Keap1: } & \text { Kelch-like ECH-associated protein 1 } \\ \text { AMPK: } & \text { AMP-activated protein kinase } \\ \text { ZNT-1: } & \text { SLC30A1 } \\ \text { MT: } & \text { Metallothionein } \\ \text { UCP2: } & \text { Uncoupling protein 2 } \\ \text { CRIP: } & \text { Cysteine-rich intestinal protein } \\ \text { CAT: } & \text { Catalase } \\ \text { CuZnSOD: } & \text { Copper-zinc superoxide dismutase } \\ \text { Tfam: } & \text { Mitochondrial transcription factor A } \\ \end{array}$

Gpx1: $\quad$ Glutathione peroxidase 1

PDHA1: $\quad$ Pyruvate dehydrogenase A1

MTF-1: Transcription factor.

\section{Data Availability}

The data used to support the findings of this study are available from the corresponding author upon request.

\section{Conflicts of Interest}

The authors have no conflicts of interest.

\section{Authors' Contributions}

Wenjie Tang and Jing Long made equal contributions to this study, so they are joint first authors.

\section{Acknowledgments}

This work was supported by the Young Elite Scientists Sponsorship Program by CAST (2019QNRC001), Special Funds for Construction of Innovative Provinces in Hunan Province (2019RS3022), "Huxiang Young Talents" projects of Hunan Province (2020RC3052), Natural Science Foundation of China (31902168 and 31872371), National Science Foundation for Outstanding Young Scholars of Hunan Province (2019JJ30017), Hunan high-level talent gathering project (2018RS3111), Guangdong Basic and Applied Basic Research Fund Project (2019A1515110852), Guangxi Key Research and Development Plan (guike AB19259012), and the Applied Basic Research Grant Project of Sichuan Province (2018JY0641).

\section{Supplementary Materials}

Supplemental Table 1 is the primers used for quantitative reverse transcription-PCR. (Supplementary Materials)

\section{References}

[1] K. H. Ibs and L. Rink, "Zinc-altered immune function," Journal of Nutrition, vol. 133, no. 5, pp. 1452S-1456S, 2003.

[2] A. Owusu-Asiedu, C. M. Nyachoti, and R. R. Marquardt, "Response of early-weaned pigs to an enterotoxigenic Escherichia coli (K88) challenge when fed diets containing spraydried porcine plasma or pea protein isolate plus egg yolk antibody, zinc oxide, fumaric acid, or antibiotic," Journal of Animal Science, vol. 81, no. 7, pp. 1790-1798, 2003.

[3] C. M. Mcdonald, K. P. Manji, K. Rodrick et al., "Daily zinc but not multivitamin supplementation reduces diarrhea and upper respiratory infections in Tanzanian infants: a randomized, double-blind, placebo-controlled clinical trial," Journal of Nutrition, vol. 145, no. 9, pp. 2153-2160, 2015.

[4] F. Alberto, M. Mara, C. D. Laura, and M. Elena, "Zinc deficiency induces membrane barrier damage and increases neutrophil transmigration in Caco-2 cells," Journal of Nutrition, vol. 138, no. 9, pp. 1664-1670, 2008.

[5] L. Noam and H. Michal, "How cellular Zn2+ signaling drives physiological functions," Cell Calcium, vol. 75, pp. 53-63, 2018. 
[6] H. N. Shi, M. E. Scott, M. M. Stevenson, and K. G. Koski, "Energy restriction and zinc deficiency impair the functions of murine $\mathrm{T}$ cells and antigen-presenting cells during gastrointestinal nematode infection," Journal of Nutrition, vol. 128, no. 1, pp. 20-27, 1998.

[7] B. Shenying and D. L. Knoell, "Zinc modulates cytokineinduced lung epithelial cell barrier permeability," American Journal of Physiology Lung Cellular \& Molecular Physiology, vol. 291, pp. L1132-L1141, 2006.

[8] R. Canali, F. Vignolini, F. Nobili, and E. Mengheri, "Reduction of oxidative stress and cytokine-induced neutrophil chemoattractant (CINC) expression by red wine polyphenols in zinc deficiency induced intestinal damage of rat," Free Radical Biology \& Medicine, vol. 28, no. 11, pp. 1661-1670, 2000.

[9] H. Aliarabi, A. Fadayifar, M. M. Tabatabaei et al., "Effect of zinc source on hematological, metabolic parameters and mineral balance in lambs," Biological Trace Element Research, vol. 168, no. 1, pp. 82-90, 2015.

[10] T. C. Huang, W. T. Chang, Y. C. Hu, B. S. Hsieh, and K. L. Chang, "Zinc protects articular chondrocytes through changes in Nrf2-mediated antioxidants," Cytokines and Matrix Metalloproteinases, Nutrients, vol. 10, p. 471, 2018.

[11] S. Mwangi, J. Timmons, T. Ao et al., "Effect of zinc imprinting and replacing inorganic zinc with organic zinc on early performance of broiler chicks," Poultry Science, vol. 96, no. 4, pp. 861-868, 2017.

[12] N. W. Shelton, M. D. Tokach, J. L. Nelssen et al., "Effects of copper sulfate, tri-basic copper chloride, and zinc oxide on weanling pig performance," Journal of Animal Science, vol. 89, no. 8, pp. 2440-2451, 2011.

[13] M. M. Bai, H. N. Liu, K. Xu et al., "Use of coated nano zinc oxide as an additive to improve the zinc excretion and intestinal morphology of growing pigs1," Journal of Animal Science, vol. 97, no. 4, pp. 1772-1783, 2019.

[14] Y. M. Bao, M. Choct, P. A. Iji, and K. Bruerton, "Effect of organically complexed copper, iron, manganese, and zinc on broiler performance, mineral excretion, and accumulation in tissues," Journal of Applied Poultry Research, vol. 16, no. 3, pp. 448-455, 2007.

[15] S. Leeson and L. Caston, "Using minimal supplements of trace minerals as a method of reducing trace mineral content of poultry manure," Animal Feed Science \& Technology, vol. 142, no. 3-4, pp. 339-347, 2008.

[16] T. Ao, J. Pierce, R. Power et al., "Effects of feeding different forms of zinc and copper on the performance and tissue mineral content of chicks," Poultry Science, vol. 88, no. 10, pp. 2171-2175, 2009.

[17] J. Yan, C. Zhang, L. Tang, and S. Y. Kuang, "Effects of organic zinc sources on the contents of amino acids and fatty acids in Sichuan chicken," Nutrition and Feedstuffs, vol. 53, no. 12, pp. 86-88, 2017.

[18] B. Zhao, A. Zhou, and X. Li, "Effects of zinc lactate on production performance and shell quality of laying hens," Science and Technology Outlook, vol. 17, pp. 28-29, 2012.

[19] G. Bai, "Research progress of zinc lactate and its application in rabbit nutrition," Sichuan Animal \& Veterinary Sciences, vol. 8, pp. 34-35, 2007.

[20] Y. Ma, Q. Huang, M. Lv et al., "Chitosan-Zn chelate increases antioxidant enzyme activity and improves immune function in weaned piglets," Biological Trace Element Research, vol. 158, no. 1, pp. 45-50, 2014.
[21] M. C. Jaramillo and D. D. Zhang, "The emerging role of the Nrf2-Keap1 signaling pathway in cancer," Genes \& Development, vol. 27, no. 20, pp. 2179-2191, 2013.

[22] D. Hu, Y. Xu, J. Xie, C. Sun, X. Zheng, and W. Chen, "Systematic evaluation of phenolic compounds and protective capacity of a new mulberry cultivar J33 against palmitic acid-induced lipotoxicity using a simulated digestion method," Food Chemistry, vol. 258, pp. 43-50, 2018.

[23] M. H. Xia, X. Y. Yan, L. Zhou et al., "p62 suppressed VK3induced oxidative damage through Keap1/Nrf2 pathway in human ovarian cancer cells," Journal of Cancer, vol. 11, no. 6, pp. 1299-1307, 2020.

[24] Y. Farbood, A. Sarkaki, M. Mahdavinia et al., "Protective effects of co-administration of zinc and selenium against streptozotocin-induced Alzheimer's disease: behavioral, mitochondrial oxidative stress, and GPR39 expression alterations in rats," Neurotoxicity Research, vol. 38, no. 2, pp. 398-407, 2020.

[25] L. He, J. Wu, W. Tang et al., "Prevention of oxidative stress by $\alpha$-ketoglutarate via activation of CAR signaling and modulation of the expression of key antioxidant-associated targets in vivo and in vitro," Journal of Agricultural and Food Chemistry, vol. 66, no. 43, pp. 11273-11283, 2018.

[26] L. Q. He, J. Long, X. H. Zhou, Y. H. Liu, T. J. Li, and X. Wu, "Serine is required for the maintenance of redox balance and proliferation in the intestine under oxidative stress," The FASEB Journal, vol. 34, no. 3, pp. 4702-4717, 2020.

[27] J. Yin, M. Wu, Y. Li et al., "Toxicity assessment of hydrogen peroxide on Toll-like receptor system, apoptosis, and mitochondrial respiration in piglets and IPEC-J2 cells," Oncotarget, vol. 8, no. 2, pp. 3124-3131, 2017.

[28] C. F. Mo, L. Wang, J. Zhang et al., "The crosstalk between Nrf2 and AMPK signal pathways is important for the antiinflammatory effect of berberine in LPS-stimulated macrophages and endotoxin-shocked mice," Antioxidants \& Redox Signaling, vol. 20, no. 4, pp. 574-588, 2014.

[29] W. Chao, L. Zhang, Z. Ying et al., "Effects of dietary zinc oxide nanoparticles on growth, Diarrhea, Mineral Deposition, Intestinal Morphology, and Barrier of Weaned Piglets," Biological Trace Element Research, vol. 185, pp. 364-374, 2018.

[30] Y. Shao, P. G. Wolf, S. Guo, Y. Guo, H. R. Gaskins, and B. Zhang, "Zinc enhances intestinal epithelial barrier function through the PI3K/AKT/mTOR signaling pathway in Caco-2 cells $\boldsymbol{w}^{2}$, Journal of Nutritional Biochemistry, vol. 43, pp. 1826, 2017.

[31] K. Ohashi, Y. Nagata, E. Wada, P. S. Zammit, M. Shiozuka, and R. Matsuda, "Zinc promotes proliferation and activation of myogenic cells via the PI3K/Akt and ERK signaling cascade," Experimental Cell Research, vol. 333, no. 2, pp. 228-237, 2015.

[32] Z. X. Song, W. D. Jiang, Y. Liu et al., "Dietary zinc deficiency reduced growth performance, intestinal immune and physical barrier functions related to NF- $\kappa$ B, TOR, Nrf2, JNK and MLCK signaling pathway of young grass carp (Ctenopharyngodon idella)," Fish \& Shellfish Immunology, vol. 66, pp. 497-523, 2017.

[33] T. Kambe, Y. Yamaguchi-Iwai, R. Sasaki, and M. Nagao, "Overview of mammalian zinc transporters," Cellular \& Molecular Life Sciences Cmls, vol. 61, no. 1, pp. 49-68, 2004.

[34] L. A. Lichten and R. J. Cousins, "Mammalian zinc transporters: nutritional and physiologic regulation," Annual Review of Nutrition, vol. 29, no. 1, pp. 153-176, 2009. 
[35] O. Beharier, S. Dror, S. Levy et al., "ZnT-1 protects HL-1 cells from simulated ischemia-reperfusion through activation of Ras-ERK signaling," Journal of Molecular Medicine, vol. 90, no. 2, pp. 127-138, 2012.

[36] J. S. Kyoung, K. Mi-Kyung, L. Young-Hoon et al., "Lower zinc bioavailability may be related to higher risk of subclinical atherosclerosis in Korean adults," PLoS One, vol. 8, article e80115, 2013.

[37] M. P. Gunderson, B. T. Nguyen, J. C. C. Reyes et al., "Response of phase I and II detoxification enzymes, glutathione, metallothionein and acetylcholine esterase to mercury and dimethoate in signal crayfish (Pacifastacus leniusculus)," Chemosphere, vol. 208, pp. 749-756, 2018.

[38] R. María, J. A. Rubiolo, T. Eva, O. P. Thomas, M. R. Vieytes, and L. M. Botana, "Crambescin C1 exerts a cytoprotective effect on HepG2 cells through metallothionein induction," Marine Drugs, vol. 13, pp. 4633-4653, 2015.

[39] O. Escobar, M. Sandoval, A. Vargas, and J. M. Hempe, "Role of metallothionein and cysteine-rich intestinal protein in the regulation of zinc absorption by diabetic rats," Pediatric Research, vol. 37, no. 3, pp. 321-327, 1995.

[40] A. A. Starkov, A. Y. Andreyev, S. F. Zhang et al., "Scavenging of $\mathrm{H} 2 \mathrm{O} 2$ by mouse brain mitochondria," Journal of Bioenergetics and Biomembranes, vol. 46, no. 6, pp. 471-477, 2014.

[41] G. Lorenzo, K. Oliver, and K. Guido, "Mitochondria: master regulators of danger signalling," Nature Reviews Molecular Cell Biology, vol. 13, pp. 780-788, 2012.

[42] T. Chitoku and D. Sabrina, "Mitochondrial UCP2 in the central regulation of metabolism," Best Practice \& Research Clinical Endocrinology \& Metabolism, vol. 28, pp. 757-764, 2014.

[43] F. Correa, V. Soto, and C. Zazueta, "Mitochondrial permeability transition relevance for apoptotic triggering in the postischemic heart," The International Journal of Biochemistry \& Cell Biology, vol. 39, no. 4, pp. 787-798, 2007.

[44] S. Diano and T. L. Horvath, "Mitochondrial uncoupling protein 2 (UCP2) in glucose and lipid metabolism," Trends in Molecular Medicine, vol. 18, no. 1, pp. 52-58, 2012.

[45] J. Yu-Bin and Y. Lei, "N-butanol extract of Capparis spinosa L. induces apoptosis primarily through a mitochondrial pathway involving $\mathrm{mPTP}$ open, cytochrome $\mathrm{C}$ release and caspase activation," Asian Pacific Journal of Cancer Prevention Apjcp, vol. 15, pp. 9153-9157, 2014.

[46] M. Singer, "The role of mitochondrial dysfunction in sepsisinduced multi-organ failure," Virulence, vol. 5, pp. 66-72, 2013.

[47] P. I. Oteiza, K. L. Olin, C. G. Fraga, and C. L. Keen, "Zinc deficiency causes oxidative damage to proteins, lipids and DNA in rat testes," Journal of Nutrition, vol. 125, pp. 823-829, 1995.

[48] X. G. Lei, J. H. Zhu, W. H. Cheng et al., "Paradoxical roles of antioxidant enzymes: basic mechanisms and health implications," Physiological Reviews, vol. 96, no. 1, pp. 307-364, 2016.

[49] S. Hojyo and T. Fukada, "Zinc transporters and signaling in physiology and pathogenesis," Archives of Biochemistry and Biophysics, vol. 611, pp. 43-50, 2016.

[50] Y. M. Song, M. H. Kim, H. N. Kim et al., "Effects of dietary supplementation of lipid-coated zinc oxide on intestinal mucosal morphology and expression of the genes associated with growth and immune function in weanling pigs," AsianAustralasian Journal of Animal Sciences, vol. 31, no. 3, pp. 403-409, 2018.
[51] T. Kensler and N. Wakabayashi, "Cell survival responses to environmental stresses via the Keap1-Nrf2-ARE pathway," Annual Review of Pharmacology and Toxicology, vol. 47, no. 1, pp. 89-116, 2007.

[52] D. Bartolini, K. Dallaglio, P. Torquato, M. Piroddi, and F. Galli, "Nrf2-p62 autophagy pathway and its response to oxidative stress in hepatocellular carcinoma," Translational Research, vol. 193, pp. 54-71, 2018.

[53] K. Zimmermann, J. Baldinger, B. Mayerhofer, A. G. Atanasov, V. M. Dirsch, and E. H. Heiss, "Activated AMPK boosts the Nrf2/HO-1 signaling axis-a role for the unfolded protein response," Free Radical Biology \& Medicine, vol. 88, pp. 417426, 2015. 